\title{
ELABORAÇÃO DE UMA BASE DE CONHECIMENTOS PARA AUXÍLIO AO DIAGNÓSTICO ATRAVÉS DA COMPARAÇÃO VISUAL DE IMAGENS MAMOGRÁFICAS
}

\author{
Marcelo Ossamu Honda
}

Dissertação apresentada à Escola de Engenharia de São Carlos da Universidade de São Paulo, como parte dos requisitos para obtenção do título de Mestre em Engenharia Elétrica

Orientador: Prof. Dr. Paulo Mazzoncini de Azevedo Marques 
À Deus.

À minha família, pelo amor, apoio e humildade em todos os momentos da minha vida.

À Silvia, por me amar, me compreender, me apoiar, ser minha amiga e ter mudado o rumo da minha vida. 
Ao professor e amigo Paulo Mazzoncini de Azevedo Marques, pela orientação, apoio, cooperação e confiança oferecidos, fundamentais para a realização deste trabalho.

À professora Annie France Frére Slaets, pela fundamental colaboração oferecida em todos os momentos.

Aos amigos e ex-professores Sérgio Koodi Kinoshita, Fábio Lúcio Meira entre muitos outros, que participaram de minha formação e me incentivaram na realização deste trabalho.

Em especial aos amigos do CHOPI: TimHunter (Lucas), Chico Bento (Roberto), BIOS (David), Fininho (Edilson), Puff (Marcelo), Mortiça (Luciene) e (André), pelo companheirismo e indispensável auxílio prestado.

Aos amigos que mesmo de longe torcem por mim.

Aos amigos e colegas conhecidos nesta etapa: Rita, Natália, integrantes dos laboratórios @ladim, @ladimMogi e me perdoem os que aqui esqueci de citar.

Ao Centro de Ciências das Imagens e Física Médica da Faculdade de Medicina de Ribeirão Preto da Universidade de São Paulo, pelo apoio e espaço para o desenvolvimento deste trabalho.

Aos professores e funcionários do Centro de Ciências das Imagens e Física Médica da Faculdade de Medicina de Ribeirão Preto da Universidade de São Paulo, principalmente ao Dr. José Antonio Hiesinger Rodrigues, pela ajuda e paciência.

Aos professores e funcionários do Departamento de Engenharia Elétrica da Escola de Engenharia de São Carlos da Universidade de São Paulo, pela ajuda, paciência e amizade.

Ao Departamento de Engenharia Elétrica da Escola de Engenharia de São Carlos da Universidade de São Paulo, pela oportunidade de realização deste trabalho.

À Fundação de Amparo à Pesquisa do Estado de São Paulo (FAPESP), pelo apoio financeiro, processo 99/04083-9.

À todos que direta ou indiretamente participaram deste trabalho. Obrigado. 


\section{Resumo}

Este trabalho apresenta o estudo e implementação de um Banco de Conhecimentos para auxiliar o diagnóstico de lesões da mama por inspeção visual, permitindo ao médico consultas através de características pictóricas da imagem e a comparação visual entre imagem investigada e imagens previamente classificadas e suas informações clínicas.

As imagens encontram-se classificadas no Banco de Conhecimentos segundo o padrão "Breast Imaging Reporting and Data Systems" (BI-RADS) do Colégio Americano de Radiologia. A seleção das imagens, informações clínicas representativas, bem como sua classificação foram realizada em conjunto com médicos radiologistas do Centro de Ciências das Imagens e Física Médica (CCIFM) da Faculdade de Medicina de Ribeirão Preto (FMRP) da Universidade de São Paulo (USP).

O processo de indexação e recuperação das imagens é baseado em atributos de textura extraídos de "Regions Of Interest" (ROIs) previamente estabelecidas em mamogramas digitalizados. Para simplificar este processo, foi utilizado a Análise de Componentes Principais (PCA), que visa a redução do número de atributos de textura e as informações redundantes existentes. Os melhores resultados obtidos foram para as ROIs 139 (Precisão $=0.80), 59($ Precisão $=0.86)$ e um valor de $100 \%$ de acerto para a ROI 40 . 


\begin{abstract}
This work presents the survey and implementation of a Database of Knowledge to aid the diagnostic of breast lesions through visual inspection, allowing the physician a search through the characteristics of the contents of the image and the visual comparison between the analysed image and the previously classified images and its clinical information.

The images are classified into the DataBase of Knowledge according to the pattern Breast Imaging Reporting and Data Systems (BI-RADS) of the American College of Radiology. The selection of the images, the representative clinical information, as well as its classification have been performed in conjunction with practictioners radiologists of the Centro de Ciências das Imagens e Física Média (CCIFM) from Faculdade de Medicina de Ribierão Preto (FMRP) from Universidade de São Paulo (USP).

The process of indexing and retrieving the images is based on characteristic of the texture extracted from the regions of interest (ROIs) previously established through scanned mammograms. To simplify this path, the Principal Components Analysis (PCA) was used it aims the reduction of the number of features of texture and the existing redundant information. The best results obtained were to the ROIs $139($ precision $=0.80), 59($ precision $=0.86)$ and a value of $100 \%$ of precision for ROI 40 .
\end{abstract}


Este trabalho teve apoio financeiro da FAPESP - Fundação de Amparo à Pesquisa do Estado de São Paulo - Processo no 99/04083-9. 


\section{Sumário}

1 Introdução 1

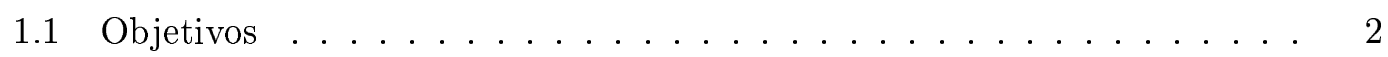

1.2 Organização desta dissertação . . . . . . . . . . . . . 3

2 Considerações gerais sobre processamento de imagens 5

2.1 Passos fundamentais em processamento de imagens . . . . . . . . . . 6

2.1 .1 Aquisição de imagens . . . . . . . . . . . . . . . 6

2.1.2 Pré-Processamento . . . . . . . . . . . . . . . . 6

2.1 .3 Segmentação . . . . . . . . . . . . . . . . . 7

2.1.4 Representação e Descrição . . . . . . . . . . . . . . 7

2.1.5 Reconhecimento e Interpretação . . . . . . . . . . . . . . 7

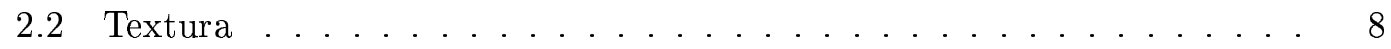

2.2 .1 Abordagem estrutural . . . . . . . . . . . . . 8

2.2 .2 Abordagem espectral . . . . . . . . . . . . . . 8

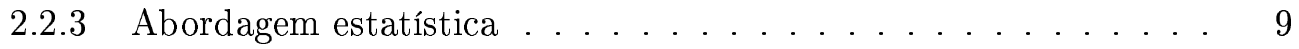

2.3 Descritores de Haralick . . . . . . . . . . . . . . . . . . . . 12

3 Caracterização de textura em imagens médicas $\quad 18$

4 Caracterização de imagens mamográficas $\quad 25$

4.1 Anatomia da mama . . . . . . . . . . . . . . . . 25

4.1 .1 Anatomia da superfície . . . . . . . . . . . . . . 26 
4.1 .2 Anatomia no plano sagital . . . . . . . . . . . . . 27

4.1.3 Anatomia no plano frontal . . . . . . . . . . . . . . 28

4.2 Tipos de tecido mamário . . . . . . . . . . . . . . . . . . . . . 29

4.3 Métodos de localização . . . . . . . . . . . . . . . . . . . . . . . . 31

4.4 Terminologia e abreviações . . . . . . . . . . . . . . . . . . . . 31

4.5 Posicionamento da mama . . . . . . . . . . . . . . . . 32

4.5 .1 Tubo de raios $\mathrm{X} \ldots \ldots \ldots \ldots \ldots \ldots$

$4.5 .2 \quad$ Compressão . . . . . . . . . . . . . . . . . . . . . 33

4.5 .3 Ampliação . . . . . . . . . . . . . . . . . . . . . . 34

4.5 .4 Dose para a paciente . . . . . . . . . . . . . . 35

4.6 Incidências . . . . . . . . . . . . . . . . . . . . . 35

4.6 .1 Craniocaudal $(\mathrm{CC}) \ldots \ldots \ldots \ldots \ldots \ldots$

4.6 .2 Oblíqua mediolateral $(\mathrm{MLO}) \ldots \ldots . \ldots . \ldots 36$

4.6.3 Craniocaudal lateralmente exagerada (CCLE) . . . . . . . . 36

4.6.4 Mediolateral (ML) - incidência lateral verdadeira . . . . . . . . 36

4.7 Classificação da mama . . . . . . . . . . . . . . . . . . . 37

4.8 Principais indicadores de lesões de mama $\ldots \ldots \ldots$

4.9 Padrão BI-RADS . . . . . . . . . . . . . . . . . . . . . . . 39

4.9 .1 Classificação dos nódulos mamários: . . . . . . . . . . . . . 40

4.9 .2 Classificação das calcificações mamárias: . . . . . . . . . . . . . . 41

$4.9 .3 \quad$ Densidade assimétrica: . . . . . . . . . . . . . . . . . . 42

4.9 .4 Alteração arquitetural: . . . . . . . . . . . . . . . . . . . 42

4.9 .5 Ducto dilatado solitário: . . . . . . . . . . . . . . . 42

4.9 .6 Adenopatia axilar: . . . . . . . . . . . . . . . . . . . . 43

5 Bancos de dados $\quad 44$

5.1 Introdução e conceitos gerais . . . . . . . . . . . . . . . 44

5.2 Modelo entidade relacionamento (ER) . . . . . . . . . . 45 
5.3 Modelo entidade relacionamento estendido . . . . . . . . . . . . . 46

5.4 Modelo relacional . . . . . . . . . . . . . . . . . . . . . 46

5.5 Normalização . . . . . . . . . . . . . . . . . . . . . 46

5.6 Álgebra relacional . . . . . . . . . . . . . . . . . . . . 47

6 Materiais e métodos $\quad 48$

6.1 Sistema operacional . . . . . . . . . . . . . . . . . . . . . . . 49

6.2 Linguagem de desenvolvimento . . . . . . . . . . . . . . . . 49

6.3 Banco de dados . . . . . . . . . . . . . . . . . . 5 50

6.4 Levantamento e digitalização dos exames mamográficos . . . . . . . . . 5 50

6.5 Classificação dos mamogramas . . . . . . . . . . . . . . 51

6.6 Extração de atributos de textura . . . . . . . . . . . . . . 52

6.7 Indexação e recuperação das imagens pelo conteúdo . . . . . . . . . . . 54

6.8 Interface de visualização $\ldots \ldots \ldots \ldots \ldots \ldots \ldots$

6.9 Avaliação de resultados . . . . . . . . . . . . . . . . . . 55

$\begin{array}{lll}7 & \text { Resultados e discussão } & \mathbf{5 9}\end{array}$

7.1 Precisão do sistema de recuperação de imagens . . . . . . . . . . . . 59

8 Conclusões $\quad 66$

8.1 Conclusões finais . . . . . . . . . . . . . . . . . 66

8.2 Sugestões para trabalhos futuros $\ldots \ldots \ldots \ldots$. . . . . . . . 67

$\begin{array}{lll}9 & \text { Anexos } & 69\end{array}$ 


\section{Lista de Figuras}

2.1 Níveis do processamento de imagens . . . . . . . . . . 6

2.2 Figura representando uma imagem com três níveis de cinza $\ldots \ldots$. . . 10

2.3 Representação da imagem e operador $\mathrm{P} \ldots \ldots$. . . . . . . . . 10

2.4 Matriz resultante . . . . . . . . . . . . . . . . . . . . . 11

2.5 Matriz de co-ocorrência . . . . . . . . . . . . . . . 11

4.1 Anatomia superficial . . . . . . . . . . . . . . . . . 26

4.2 Corte sagital da mama . . . . . . . . . . . . . . . 27

4.3 Corte sagital da mama . . . . . . . . . . . . . . . . . . 28

4.4 Mama - vista anterior . . . . . . . . . . . . . . . 28

4.5 Mama - vista anterior (três tipos de tecidos) . . . . . . . . . . 30

4.6 Mamografia . . . . . . . . . . . . . . . . . . . . . . 30

4.7 Localização da mama - sistema de quadrantes e do relógio . . . . . . . 31

4.8 Posicionamento de paciente . . . . . . . . . . . . . . . . 33

4.9 Efeito da compressão da mama . . . . . . . . . . . . . . . . 34

4.10 Ampliação da mama . . . . . . . . . . . . . . . . . 35

4.11 Incidência CC . . . . . . . . . . . . . . . . . . . . 36

4.12 Incidência MLO . . . . . . . . . . . . . . . . . . . . . 36

4.13 Incidência CCLE . . . . . . . . . . . . . . . . . . . . 37

4.14 Incidência ML . . . . . . . . . . . . . . . . . . . . . 37

5.1 Ambiente de sistema de banco de dados . . . . . . . . . . . . . 45 
5.2 Descrição da tabela . . . . . . . . . . . . . . . . . . . . 47

6.1 Diagrama de blocos representando o processo de indexação, armazenamento e recuperação de imagens . . . . . . . . . . . . . . 48

6.2 Exemplo de interfaces gráficas do sistema - menu principal e cadastro de exames . . . . . . . . . . . . . . . . . . . 5 50

6.3 Exemplo de mamogramas digitalizados; (a) crânio caudal direita, (b) oblíqua direita, (c) axilar direita e (d) ROI. . . . . . . . . . . . 51

6.4 Exemplo de valores extraídos de uma ROI . . . . . . . . . . . . . 52

6.5 Calculo da matriz SGLD . . . . . . . . . . . . . . . . . 53

6.6 Resumo dos passos para Análise de Componentes Principais . . . . . . . 54

6.7 Exemplo de um código de consulta . . . . . . . . . . . . . . . 55

6.8 Visualizador de imagens . . . . . . . . . . . . . . . . . 56

6.9 No conjunto de imagens (A) é apresentado a ROI utilizada para consulta com suas respectivas imagens e no conjunto de imagens (B) é apresentado a ROI recuperada pelo sistema com suas respectivas imagens . . . . . 58

7.1 (A) imagem utilizada para consulta - imagem $40 \ldots \ldots$. . . . . . . 63

7.2 (A) imagem utilizada para consulta - imagem $145 \ldots . . \ldots 64$

7.3 (A) imagem utilizada para consulta - imagem $108 \ldots . . \ldots 65$

8.1 Exemplo de técnica de segmentação de imagens para separar o tecido mamário do fundo do filme (Cedido por Roberto Rodrigues Pereira Junior $-\mathrm{SEL} / \mathrm{EESC} / \mathrm{USP}) \ldots \ldots \ldots \ldots \ldots \ldots$

9.1 (A) imagem utilizada para consulta - imagem $5 \ldots \ldots . \ldots 70$

9.2 (A) imagem utilizada para consulta - imagem $13 \ldots 7 . \ldots 70$

9.3 (A) imagem utilizada para consulta - imagem $23 \ldots \ldots 71$

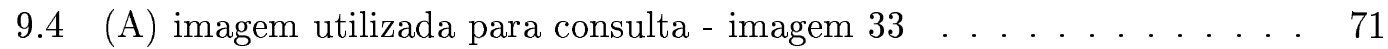

9.5 (A) imagem utilizada para consulta - imagem $59 \ldots \ldots 72$ 
9.6 (A) imagem utilizada para consulta - imagem $129 \ldots . . \ldots 72$

9.7 (A) imagem utilizada para consulta - imagem $139 \ldots 73$

9.8 (A) imagem utilizada para consulta - imagem $152 \ldots \ldots 73$

9.9 (A) imagem utilizada para consulta - imagem $161 \ldots \ldots . . \ldots 74$

9.10 (A) imagem utilizada para consulta - imagem $208 \ldots \ldots . \ldots 75$ 


\section{Lista de Tabelas}

4.1 Terminologia e abreviações da mamografia . . . . . . . . . . . . . . 32

6.1 Total de imagens digitalizadas por categorias . . . . . . . . . . . . 51

6.2 Autovalores gerados pelo PCA . . . . . . . . . . . . . 54

6.3 Índice de similaridade $\ldots \ldots \ldots \ldots . \ldots \ldots$

7.1 Resultado da avaliação do especialista e valor de Precisão para ROIs . . 59

7.2 Resultado da avaliação do especialista e valor de Precisão para os casos completos . . . . . . . . . . . . . . . . 6 6 60

7.3 Média e desvio padrão na avaliação das ROIs . . . . . . . . . . . . 62

7.4 Média e desvio padrão na avaliação dos casos completos . . . . . . . . 62 


\section{Capítulo 1}

\section{Introdução}

A Organização Mundial de Saúde estimou que em 2000, no mundo todo, ocorreram mais de 10 milhões de novos casos de câncer, sendo os tipos mais comuns o de pulmão entre os homens e o de mama entre as mulheres. Já no Brasil, o Instituto Nacional do Câncer (INCA), estima que em 2001, serão registrados 305.330 casos novos e 117.550 óbitos por câncer. Estima-se que o principal câncer a acometer a população brasileira será o câncer de pele não melanoma (54.460 casos), seguido pelas neoplasias malignas da mama feminina (31.590 casos) [INCA (2001)]. Ainda segundo o INCA, foi observado um considerável aumento da taxa de mortalidade de 1979 a 1998. Esta tendência é consistente com a de países desenvolvidos, nos quais a urbanização levou ao aumento de fatores de risco para o câncer de mama, como por exemplo, a idade tardia da primeira gravidez [INCA (2001)]. Segundo levantamento estatístico sobre mulheres americanas com câncer de mama, as taxas de sobrevivência por 5 anos geralmente são maiores, em torno de $93 \%$, para o tumor detectado no estágio inicial, caindo para $72 \%$ em estágios intermediários e de apenas $18 \%$ para estágios avançados, conforme afirmam Laine et al. [LAINE et al. (1995)].

Esses fatores tem levado ao direcionamento de várias pesquisas para o desenvolvimento de métodos mais eficazes para a detecção e tratamento precoce do câncer de mama. Sendo a detecção precoce e a remoção do tumor na fase inicial considera- 
dos a estratégia mais eficiente na redução da taxa de mortalidade das pacientes [SHEN et al. (1993)]. O diagnóstico precoce pode ser basicamente de dois tipos: (a) por imagem e (b) auto-exame. A mamografia, dos métodos de diagnóstico por imagem atualmente disponíveis, é ainda o mais eficaz para a detecção do câncer precoce, como afirmam vários autores, entre eles Morrow et al. [MORROW et al. (1992)], Lefebvre et al. [LEFEBVRE et al. (1994)], Petrick et al. [PETRICK et al. (1996)] e Giger [GIGER (1999)]. A mamografia apresenta altas resoluções (espacial e contraste), fundamentais para o registro de imagens de lesões pequenas. Porém, segundo Kocur et al. [KOCUR et al. (1996)] e Giger [GIGER (1999)], de 10 a 30\% dos casos de câncer de mama, incluindo os tumores palpáveis, não são detectados com a rotina da mamografia, sendo aproximadamente $60 \%$ desses falsos-negativos evidenciados através de uma revisão detalhada dos mamogramas anteriores. Esta falha pode ser atribuída a vários fatores incluindo baixa qualidade da imagem, fadiga do radiologista e descuido humano. Por outro lado, aproximadamente $75 \%$ dos casos diagnosticados como suspeitos, e enviados para biópsia, apresentam diagnóstico benigno.

Neste contexto de incerteza diagnóstica é que se torna interessante a elaboração de um Banco de Conhecimentos que permita ao médico a comparação visual entre a imagem investigada e imagens previamente classificadas e seus laudos histopatológicos, proporcionando ao especialista um método de auxílio ao diagnóstico e buscando maior grau de confiabilidade no seu laudo.

\subsection{Objetivos}

O objetivo principal desse trabalho é a elaboração de um Banco de Conhecimentos para auxiliar o diagnóstico de lesões de mama por inspeção visual, permitindo ao médico consultas através de características pictóricas da imagem e a comparação visual entre a imagem investigada e imagens previamente classificadas e seus laudos histopatológicos. As imagens estão organizadas em um Banco de Conhecimento segundo o padrão "Breast 
Imaging Reporting and Data Systems" (BI-RADS) do Colégio Americano de Radiologia.

Para tanto, o sistema deve ser capaz de realizar a extração de atributos de textura, de "Regions Of Interest" (ROIs) de mamogramas digitalizados. Essa descrição e/ou representação da imagem deve ser de um formato apropriado para identificar um conjunto de informações relacionadas a este valor estatístico. Utilizou-se da Análise de Componentes Principais (PCA), para simplificar o processo de indexação e recuperação das imagens, visando a redução do número de atributos de textura e as informações redundantes existentes.

Deve-se ressaltar que o objetivo desse projeto não é de um sistema que substitua a análise do médico, mas sim um sistema de auxílio, proporcionando um potencial maior ao diagnóstico.

\subsection{Organização desta dissertação}

Esta dissertação é dividida em 8 capítulos. O primeiro traz uma introdução e apresentação dos objetivos desta pesquisa.

O segundo capítulo apresenta considerações gerais sobre processamento de imagens, seus passos fundamentais, definição de textura e seus tipos de abordagens e os descritores de textura utilizados neste trabalho.

O terceiro capítulo traz uma revisão de trabalhos desenvolvidos que utilizaram atributos de textura para caracterização de imagens médicas.

O quarto capítulo apresenta uma caracterização de imagens mamográficas e a metodologia utilizada para classificação segundo o padrão BI-RADS.

O quinto capítulo apresenta considerações gerais sobre banco de dados.

O sexto capítulo descreve os materiais e métodos utilizados na implementação deste trabalho.

O sétimo capítulo apresenta os resultados e discussão deste trabalho.

No oitavo capítulo encontram-se as conclusões do trabalho realizado e também su- 
gestões para trabalhos futuros sobre o assunto.

No nono capítulo encontram-se os anexos.

Ao final são apresentadas as referências bibliográficas utilizadas. 


\section{Capítulo 2}

\section{Considerações gerais sobre}

\section{processamento de imagens}

O interesse por métodos de processamento de imagens originou-se a partir de duas áreas de aplicação: a melhoria da informação contida na imagem para interpretação humana e o processamento para análise automática da imagem via máquina [GONZALEZ \& WOODS (1993)].

Uma imagem digital pode ser considerada como uma matriz em que os índices das linhas e colunas identificam um ponto na imagem e os correspondentes valores dos elementos da matriz são chamados de "pixel" (abreviatura de "picture element"). Essa matriz pode ser representada por uma função $f(x, y)$ onde $x$ e y representam as coordenadas do ponto na matriz e $\mathrm{f}(\mathrm{x}, \mathrm{y})$ o valor desse ponto. Assim o valor de um "pixel" representa o seu nível de cinza [GONZALEZ \& WOODS (1993)].

Essa representação matemática decorre da facilidade de manipular o seu conteúdo através de processamento de imagens, visando a extração de características relevantes [BALLARD \& BROWN (1982)].

Segundo Low [LOW (1991)], o processamento de imagens pode ser dividido em três níveis (Figura 2.1): baixo, médio e alto.

O processamento de baixo nível (ou pré-processamento) consiste em procedimentos 
que visam melhorar a qualidade das imagens obtidas.

O nível médio (ou segmentação) consiste em separar os seus elementos constituintes.

O alto nível consiste em reconhecer os objetos segmentados e classificá-los.

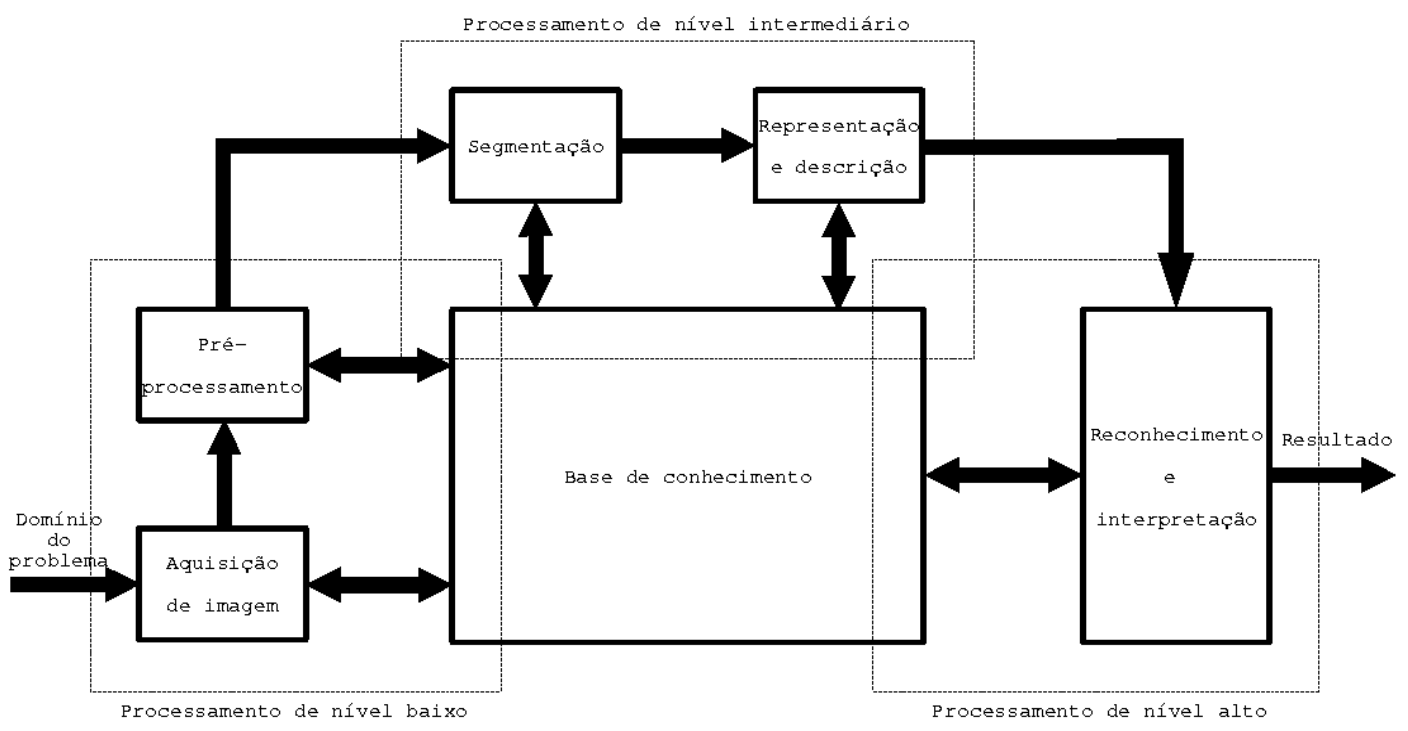

Figura 2.1: Níveis do processamento de imagens

\subsection{Passos fundamentais em processamento de imagens}

\subsubsection{Aquisição de imagens}

Este é o primeiro passo do processo, sendo, caracterizado pela existência de um sensor para obtenção de imagem, que produza um sinal elétrico de saída proporcional ao nível de energia recebida e um dispositivo para conversão da saída elétrica para a forma digital [GONZALEZ \& WOODS (1993)].

\subsubsection{Pré-Processamento}

É constituído por técnicas para melhorar a imagem (realce de contraste, remoção de ruídos entre outras) de forma a aumentar as chances de sucesso dos processos seguintes [GONZALEZ \& WOODS (1993)]. 


\subsubsection{Segmentação}

Definida, em termos gerais, como subdivisão de uma imagem de entrada em partes ou objetos constituintes, é geralmente considerada o primeiro passo em análise de imagens. O nível até o qual essa subdivisão deve ser realizada depende do problema à ser resolvido. Ou seja, a segmentação deve parar quando os objetos de interesse na aplicação tiverem sido isolados. Um processo de segmentação automatizado é um dos processos mais difíceis em processamento de imagens e pode determinar o eventual sucesso ou fracasso na análise [GONZALEZ \& WOODS (1993)].

\subsubsection{Representação e Descrição}

Referem-se à noção de que as imagens devem ser representadas e descritas em um formato apropriado para o processamento computacional. Dada a necessidade do sistema, podemos escolher entre dois tipos de representação: (1) representação da região pelas características externas (fronteiras), ou (2) por suas características internas (os "pixels" que compõem a região). A representação por fronteira é adequada quando o interesse se concentra na característica de formas externas e a representação interna é adequada às propriedades de cor e textura, por exemplo. Nada impede a utilização dos dois tipos de representação concomitantemente. A descrição, também chamada de seleção de características, procura extrair características que resultem em alguma informação quantitativa de interesse ou que sejam básicas para a discriminação entre classes de objetos [GONZALEZ \& WOODS (1993)].

\subsubsection{Reconhecimento e Interpretação}

Reconhecimento é o processo que atribui um rótulo a um objeto, baseado em informações fornecidas pelos seus descritores. A interpretação envolve a atribuição de significado a um conjunto de objetos reconhecidos [GONZALEZ \& WOODS (1993)]. 


\subsection{Textura}

Uma definição de textura pode ser dada como um atributo representando a disposição espacial dos níveis de cinza dos "pixels" em uma região [CASTLEMAN (1996)].

Considerado como um importante modelo para a descrição de regiões, esse descritor fornece intuitivamente medidas de propriedades como suavidade, rugosidade e regularidade [GONZALEZ \& WOODS (1993)]. Normalmente uma característica de textura é independente da posição do objeto, orientação, tamanho, forma e média dos níveis de cinza (brilho) [CASTLEMAN (1996)].

As três principais abordagens usadas em processamento de imagem para a descrição de textura são a estrutural, a espectral e a estatística.

\subsubsection{Abordagem estrutural}

Trata a descrição de textura como arranjos de primitivas de imagem. A idéia básica é que uma primitiva da textura pode ser usada na formação de padrões complexos através de algumas regras que organizem os arranjos possíveis. Vários padrões de textura podem ser gerados apenas variando-se a regra empregada [GONZALEZ \& WOODS (1993)] e [TOURASSI (1999)].

\subsubsection{Abordagem espectral}

É baseada nas propriedades da transformada de Fourier de uma imagem, que contém informações completas da textura. Desta maneira, pode-se utilizar o espectro para calcular atributos da imagem. A detecção e interpretação das características do espectro são freqüentemente simplificadas expressando-se o espectro em coordenadas polares [CASTLEMAN (1996)], [GONZALEZ \& WOODS (1993)] e [TAKAHASHI et al. (2000)]. Um exemplo de abordagem espectral é o uso do calculo de fractais para caracterização da textura de uma imagem [FREDERICK (2000)]. 


\subsubsection{Abordagem estatística}

Caracteriza textura como suave, áspera e granular, entre outras. Uma das abordagens estatísticas mais simples para a descrição de textura é através dos momentos do histograma de níveis de cinza de uma imagem ou de uma região. Seja $z$ um variável aleatória denotando a intensidade discreta de uma imagem e seja $p(z i), i=1,2, \ldots, L$ o histograma correspondente, sendo que $L$ é o número de níveis distintos de intensidade. O n-ésimo momento de $z$ em torno da média é dado por:

$$
\mu_{n}(z)=\sum_{i=1}^{L}\left(z_{i}-m\right)^{n} p\left(z_{i}\right)
$$

em que $m$ é o valor médio de $z$ (a intensidade média).

$$
m=\sum_{i=1}^{L} z_{i} p\left(z_{i}\right)
$$

O segundo momento (também chamado de variância e denotado por $\sigma^{2}(z)$ ) possui uma importância particular para a descrição de textura, sendo uma medida de contraste de nível de cinza que pode ser usada no estabelecimento de descritores de suavidade relativa. Por exemplo, a medida

$$
R=1-\frac{1}{1+\sigma^{2}(z)}
$$

é 0 para áreas de intensidade constante $\left(\sigma^{2}(z)=0\right.$ se todos os $z i$ 's possuírem o mesmo valor) e se aproxima de 1 para grandes valores de $\sigma^{2}(z)$. O Terceiro momento é uma medida de anti-simetria do histograma, enquanto o quarto momento é uma medida de seu achatamento ou planaridade. O quinto e os outros momentos mais altos não são facilmente relacionados ao formato do histograma, mas podem fornecer informação 
quantitativa adicional para o conteúdo de textura [GONZALEZ \& WOODS (1993)].

Medidas de textura calculadas apenas a partir do histograma de Primeira ordem sofrem limitação de não carregarem informações sobre a posição relativa dos "pixels" em função uns dos outros. Uma maneira de trazer essa informação ao processo de análise de textura é considerar não apenas a distribuição de intensidade, mas também as posições dos "pixels" com valores de intensidade iguais ou similares [GONZALEZ \& WOODS (1993)].

Seja $P$ um operador de posição e seja $\mathbf{A}$ uma matriz $k \times k$ cujo elemento $a_{i j}$ é o número de vezes que pontos com o nível de cinza $z_{i}$ ocorrem (na posição especificada por $P$ ) relativamente a pontos com nível de cinza $z_{j}$, com $1 \leq i, j \leq K$. Por exemplo, considere uma imagem com três níveis de cinza, $z_{1}=0, z_{2}=1$ e $z_{3}=2$, como sendo representada pela figura 2.2 , a definição do operador de $\mathrm{P}$ como um "pixel" à direita

$\begin{array}{lllll}0 & 0 & 0 & 1 & 2 \\ 1 & 1 & 0 & 1 & 1 \\ 2 & 2 & 1 & 0 & 0 \\ 1 & 1 & 0 & 2 & 0 \\ 0 & 0 & 1 & 0 & 1\end{array}$

Figura 2.2: Figura representando uma imagem com três níveis de cinza

e um "pixel" abaixo (135 graus) (Figura 2.3) leva à seguinte matriz 3 X 3 A (Figura

135 graus

Figura 2.3: Representação da imagem e operador P 
2.4) sendo que, por exemplo, $a_{11}$ é o número de vezes que um ponto com nível de cinza

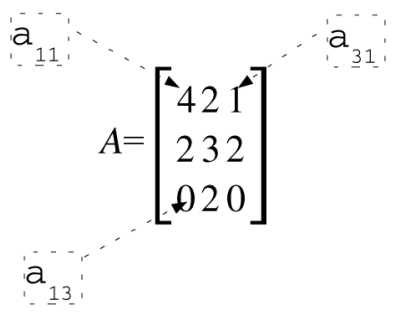

Figura 2.4: Matriz resultante

$\mathrm{z}_{1}=0$ aparece em um "pixel" abaixo e um à direita do "pixel" com o nível de cinza $z_{1}=0$, enquanto que $a_{13}$ é o número de vezes que um ponto com nível de cinza $z_{1}=0$ aparece em um "pixel" abaixo e um à direita do "pixel" com o nível de cinza igual a $z_{3}=2$. O tamanho de $\mathbf{A}$ é estritamente determinado pelo número de níveis distintos de cinza da imagem. Portanto, a aplicação usualmente requer que as intensidades sejam requantizadas em um número menor de níveis de cinza, de maneira a manter o tamanho da matriz manipulável [GONZALEZ \& WOODS (1993)].

Seja $\mathbf{n}$ o número total de pares de ponto em uma imagem que satisfaçam $\mathbf{P}$ (no exemplo anterior $\mathbf{n}=16$ ). Se uma matriz $\mathbf{C}$ for formada dividindo-se cada elemento de $\mathbf{A}$ por $\mathbf{n}$, então $c_{i j}$ será uma estimativa da probabilidade conjunta de um par de pontos satisfazendo $\mathbf{P}$ possuir os valores $\left(z_{i}, z_{j}\right)$. A matriz $\mathbf{C}$ (Figura 2.5 ) é chamada de

$$
C=\left[\begin{array}{lll}
0.2500 & 0.1250 & 0.0625 \\
0.1250 & 0.1875 & 0.1250 \\
0.0000 & 0.1250 & 0.0000
\end{array}\right]
$$

Figura 2.5: Matriz de co-ocorrência

matriz de co-ocorrência de níveis de cinza (SGLD - "Spatial Gray Level Dependence") [GONZALEZ \& WOODS (1993)].

Uma vez que $\mathbf{C}$ depende de $\mathbf{P}$, a presença de uma dada textura pode ser detectada 
através da escolha de um operador de posição apropriado. A idéia básica está em analisar uma dada matriz $\mathbf{C}$, categorizando a textura de uma região sobre a qual a matriz foi calculada através da quantificação do conteúdo da matriz utilizando-se descritores [GONZALEZ \& WOODS (1993)]. Como exemplo pode-se citar os descritores de textura sugeridos por Haralick et al. [HARALICK et al. (1973)].

\subsection{Descritores de Haralick}

Haralick et al. [HARALICK et al. (1973)] sugerem 14 descritores de textura extraídos da matriz SGLD: Variância, Correlação, Contraste, Entropia, Soma da Entropia, Diferença da Entropia, Momento da Diferença Inversa (MDI), Média da Soma, Variância da Soma, Média da Diferença, Variância da Diferença, Energia, Medida de Informação de Correlação 1 (MIC1), e Medida de Informação de Correlação 2 (MIC2) [HARALICK et al. (1973)].

Sejam $\boldsymbol{n}$ o número de níveis de cinza da imagem e $\boldsymbol{p}(\boldsymbol{i}, \boldsymbol{j})$ sua matriz de co-ocorrência, os descritores de Haralick podem ser definidos como se segue:

Variância (Equação 2.4) é um indicador da variação da tonalidade de fundo da imagem [FREDERICK (2000)].

$$
\text { Variância }=\sum_{\substack{n-1 \\ i=0}} \sum^{j=0}\left(i-\mu_{x}\right)\left(i-\mu_{y}\right) p(i, j)
$$

Correlação (Equação 2.5) é um indicador de uma estrutura implícita na textura. O valor absoluto dessa medida será maior se a imagem tiver algum tipo de estrutura como um fundo suave ou repetidas bordas sobre uma dada região [FREDERICK (2000)]. 


$$
\text { Correlacão }=\frac{\begin{array}{cc}
n-1 & n-1 \\
\sum & \sum \quad\left(i-\mu_{x}\right)\left(j-\mu_{y}\right) p(i, j)
\end{array}}{\sigma_{x} \sigma_{y}}
$$

As médias e varianças são dadas por:

$$
\begin{aligned}
& n-1 \\
& n-1 \\
& \mu_{x}=\sum i p_{x}(i) \\
& p_{x}(i)=\sum p(i, j) \\
& i=0 \\
& j=0 \\
& n-1 \\
& n-1 \\
& \mu_{y}=\sum j p_{y}(j) \\
& p_{y}(i)=\sum p(i, j) \\
& j=0 \\
& i=0 \\
& n-1 \\
& n-1 \\
& \sigma_{x}^{2}=\sum\left(i-\mu_{x}\right)^{2} p_{x}(i) \\
& i=0 \\
& \sigma_{y}^{2}=\quad \sum\left(j-\mu_{y}\right)^{2} p_{y}(i) \\
& j=0
\end{aligned}
$$

Contraste (Equação 2.6) é uma estimativa da média da variação quadrática do nível de cinza entre pares de pontos da imagem. Texturas com baixo contraste tendem a ter valores menores que as com alto contraste, para as quais a variação do nível de cinza é maior e mais provável (embora ruído e texturas rugosas tendam a ter um alto valor para essa medida) [FREDERICK (2000)].

$$
\text { Contraste }=\sum_{\substack{n-1 \\ i=0}} \sum_{j=0}(|i-j|)^{2} p(i, j)
$$

Entropia (Equação 2.7) é um indicador de quantidade de informação propiciado pelas interações entre os "pixels" da imagem [FREDERICK (2000)]. 


$$
\begin{gathered}
n-1 \quad n-1 \\
\text { Entropia }=-\sum_{i=0} \sum_{j=0} p(i, j) \log _{2}[p(i, j)]
\end{gathered}
$$

Soma da Entropia (Equação 2.8) é um indicador da quantidade de informações entre pares de "pixels" de um fundo [FREDERICK (2000)].

$$
\text { Soma da Entropia }=-\sum_{K=0}^{2 n-2} p_{x+y}(k) \log _{2}\left[p_{x+y}(k)\right]
$$

onde:

$$
\begin{gathered}
p_{x+y}(k)=\sum_{i=0 \quad}^{n-1} \quad n-1 \\
i=0 \\
\mathrm{i}+\mathrm{j}=\mathrm{k}, \mathrm{k}=0, \ldots ., 2 \mathrm{n}-2
\end{gathered}
$$

Diferença de Entropia (Equação 2.9) é similar à Soma da Entropia [FREDERICK (2000)].

$$
\begin{gathered}
2 n-2 \\
\text { Diferenca da Entropia }=-\sum_{K=0} p_{x-y}(k) \log _{2}\left[p_{x-y}(k)\right]
\end{gathered}
$$

onde:

$$
\begin{gathered}
p_{x-y}(k)=\sum_{i=0} \sum^{n-1} \quad n-1 \\
i=0 \\
|\mathrm{i}-\mathrm{j}|=\mathrm{k}, \mathrm{k}=0, \ldots, \mathrm{n}-1
\end{gathered}
$$

Momento da Diferença Inversa (Equação 2.10) é um indicador da média de tonali- 
dades entre pares de "pixels" do fundo [FREDERICK (2000)].

$$
M D I=\sum_{i=0}^{n-1} \sum_{j=0}^{n-1} \frac{1}{1+(i-j)^{2}} p(i, j)
$$

Média da Soma (Equação 2.11) é um indicador de pequenas mudanças e texturas sutis [FREDERICK (2000)].

$$
\text { Média da Soma }=\sum_{k=0}^{2 n-2} k p_{x+y}(k)
$$

Variância da soma (Equação 2.12) é um indicador da variação da tonalidade do fundo [FREDERICK (2000)].

$$
\text { Varianca da Soma }=\sum_{k=0}^{2 n-2}(k-\text { Média da Soma })^{2} p_{x+y}(k)
$$

Média da Diferença ou Coeficiente de Máxima Correlação (Equação 2.13) é baseado nos autovalores de uma função da matriz SGLD normalizada que freqüentemente é difícil de ser obtida devido a não homogeneidade da distribuição de níveis de cinza [FREDERICK (2000)].

$$
\text { Média da Diferenca }=\sum_{k=0}^{n-1} k p_{x-y}(k)
$$

Variância da Diferença (Equação 2.14) é similar a Variância da Soma mas com a média centrada em zero [FREDERICK (2000)]. 


$$
\text { Variânciada Diferenca }=\sum_{k=0}^{n-1}(k-\text { Médiada Soma })^{2} p_{x-y}(k)
$$

Energia ou Segundo Momento Angular (Equação 2.15) é um indicador da uniformidade ou suavidade. Texturas homogêneas terão um alto valor de energia em comparação com texturas não homogêneas, em função das texturas suaves possuírem densidades mais concentradas que as texturas rugosas. Texturas rugosas têm densidades com alto espalhamento ou variância [FREDERICK (2000)].

$$
\text { Energia ou Segundo Momento Angular }=\sum_{\substack{n-1 \\ i=0}} \sum_{j=0}\{p(i, j)\}^{2}
$$

MIC1 (Equação 2.16) é um indicador da correlação baseado na medida da entropia para elementos independentes e pares de elementos na imagem [FREDERICK (2000)].

$$
M I C_{1}=\frac{\text { Entropia }-H_{1}}{\max \left|H_{x}, H_{y}\right|}
$$

MIC2 (Equação 2.17) é a media da correlação baseada na similaridade entre entropias de elementos independentes da imagem e pares de elementos da imagem [FREDERICK (2000)].

$$
M I C_{2}=\sqrt{1-\exp \left[-2\left(H_{2}-\text { Entropia }\right)\right]}
$$

onde: 


$$
\begin{gathered}
n-1 \\
H_{x}=-\quad \sum p_{x}(i) \log _{2}\left[p_{x}(i)\right] \\
i=0 \\
n-1 \\
H_{y}=-\quad \sum \quad p_{y}(j) \log _{2}\left[p_{y}(j)\right] \\
\quad j=0 \\
H_{1}=-\quad n-1 \\
\quad \sum \quad p(i, j) \log _{2}\left[p_{x}(i) p_{y}(j)\right] \\
H_{2}=-\quad j=0 \\
n-1 \quad n-1 \\
\quad \sum \quad p_{x}(i) p_{y}(j) \log _{2}\left[p_{x}(i) p_{y}(j)\right] \\
i=0 \quad j=0
\end{gathered}
$$

Estes descritores têm sido amplamente utilizados em procedimentos de representação e descrição de ROIs baseadas nas características internas de textura, possuindo de modo geral alta correlação com as características visuais das imagens [CASTLEMAN (1996)]. 


\section{Capítulo 3}

\section{Caracterização de textura em}

\section{imagens médicas}

Segundo Haralick et al. [HARALICK et al. (1973)], textura é uma das características mais importantes usadas na identificação de objetos ou regiões de interesse na imagem. Em seu trabalho, estão descritas algumas características de textura baseadas na matriz SGLD, que calculam a probabilidade de ocorrência combinada de direção e distância entre pares de "pixel" de tonalidades semelhantes. Foram usados dois tipos de regras de decisão: uma para a qual as regiões de decisão são poliedros convexos e outra na qual as regiões de decisão são paralelepípedos retangulares. Em cada experimento os dados foram divididos em duas partes, um conjunto de treinamento e um conjunto de teste. A precisão de identificação para o conjunto de teste foi de $89 \%$ para imagens microscópicas, $83 \%$ para imagens aéreas e $82 \%$ para imagens espaciais. Estes resultados indicam que as características de textura têm uma aplicabilidade geral para uma larga variedade de problemas de classificação de imagem.

Em 1993, Basset et al. [BASSET et al. (1993)], realizaram um estudo utilizando atributos de texturas proposto por Haralick et al. [HARALICK et al. (1973)], calculados de matrizes SGLD de ROIs de imagens de ultra-som para discriminação de tecidos de próstata em normal, benigno ou câncer. O resultado obtido foi de $78 \%$ de classifi- 
cação bem sucedida, tendo os autores concluído como um bom percentual, dada que as imagens utilizadas não podiam ser discriminadas visualmente.

Em 1994, Petrosian et al. [PETROSIAN et al. (1994)], desenvolveram um sistema "Computer Aided Diagnosis" (CAD) para auxiliar o radiologista na interpretação de mamogramas. Os autores investigaram os atributos de textura propostos por [HARALICK et al. (1973)] para distinguir regiões contendo nódulos em mamogramas. Foram utilizadas ROIs com parenquima normal e com nódulos de vários graus de visibilidade. A matriz SGLD de cada ROI foi calculada e 8 atributos de textura foram calculados das matrizes de SGLD, sendo analisadas a correlação e as propriedades das distâncias entre classes de atributos de textura. A performance do classificador foi avaliada selecionando-se os atributos de textura com diferentes combinações que modificaram o esquema de classificação da árvore de decisão. A classificação ocorreu com $89 \%$ de sensibilidade ${ }^{1}$ e $76 \%$ de especificidade ${ }^{2}$, obtidas pela ordenação dos atributos Média da Soma, Correlação e Energia, durante os processos de treinamento. Com o método "leave-one-out" (método que proporciona uma avaliação da generalização do classificador), os resultados dos testes foram $76 \%$ de sensibilidade e $64 \%$ de especificidade, demonstrando a possibilidade de usar informações de texturas para classificação de nódulos e tecidos normais.

Em 1998, Chan et al. [CHAN et al. (1998)], desenvolveram um método computadorizado para extração e classificação de microcalcificações como malignas ou benignas em mamogramas digitalizados. Foram utilizados atributos morfológicos que descrevem o tamanho, forma e contraste nas imagens segmentadas e atributos de textura propostos por Haralick et al. [HARALICK et al. (1973)], calculados de matrizes SGLD. Uma técnica de seleção de atributos baseada em um "Genetic Algorithm" (GA) foi utilizado para selecionar o melhor subconjunto de atributos. Foram utilizadas 145 ROIs contendo microcalcificações adquiridas no Departamento de Radiologia da Universidade de

\footnotetext{
${ }^{1}$ Sensibilidade é a taxa de verdadeiro-positivo, onde o verdadeiro-positivo é o reconhecimento da existência de um sinal quando este está presente na imagem [GIGER (1999)].

${ }^{2}$ Especificidade é definida como (1-fração de falso-positivo) das imagens, ou seja, a fração de imagens corretamente identificada como não tendo sinal [GIGER (1999)].
} 
Michigan (82 benignas e 63 malignas) e classificadas por um radiologista experiente a visibilidade de cada "cluster" de microcalcificações ( 1 obvia e 5 discretas). Os autores analisaram os resultados, comparando as áreas das curvas ROC, e concluíram que os atributos de textura $(\mathrm{A} z=0.84)$ demonstram ser mais efetivos que os atributos morfológicos $(\mathrm{A} z=0.79)$, quando utilizados separadamente, pois a melhor classificação ocorreu quando foram utilizados juntos $(\mathrm{A} z=0.89)$.

Também em 1998, Gutta et al. [GUTTA et al. (1998)], desenvolveram uma ferramenta CAD para classificação de lesões de mama, sendo utilizada como segunda opinião para diminuir as classificações erradas. Os autores destacam que a maioria das ferramentas CAD operam sobre extrações de característica discriminantes. Porém, o raciocínio do radiologista sobre o significado de uma mamografia é baseado em um contexto visual complexo, o que torna difícil a expressão adequada desse contexto em representações discriminantes. Nesse sentido, a principal contribuição dada pelos autores foi a introdução da indexação e recuperação de imagens por atributos pictóricos. A indexação e recuperação das imagens foram feitas através do treinamento de uma arquitetura hibrida com dois classificadores "Radial Basis Functions" (RBF) (semelhante a uma "Artificial Neural Network" (ANN) "backpropagation" de três camadas) e intuitiva "Decision Tree" (DT) (construtor de regras para classificação de objetos), utilizando-se 10 ROIs (5 malignas e 5 benignas) previamente rotuladas. Foram utilizadas para teste 37 imagens sendo 20 benignas e 17 malignas da base de dados "The Mammographic Images Analysis Society" (MIAS). Cada ROI possui associado os respectivos mamogramas e o histórico histopatológico da paciente. Os autores concluíram em seus experimentos iniciais que o comportamento com duas classes conhecidas (benigna e maligna), confirmaram que o sistema implementado pode recuperar ROIs similares qualitativamente e quantitativamente.

Em 1999, Kim e Park [KIM \& PARK (1999)], realizaram um estudo comparativo dos métodos de análise de textura na deteç̧ão de microcalcificações em mamogramas digitalizados. Os autores compararam o método "K-Nearest Neighbor" (K-NN), pro- 
posto por eles, com métodos de análise de textura convencionais tais como: matriz SGLD, método "run-length" de nível de cinza e método da diferença de níveis de cinza. Atributos de textura extraídos por esses métodos foram utilizados para classificar ROIs em positivas, contendo microcalcificações agrupadas, e ROIs negativas, contendo tecidos normais. Uma ANN "backpropagation" de três camadas foi usada como classificador. Os resultados da ANN para os métodos de análise de textura foram avaliados através das curvas "Receiver Operating Characteristics" (ROC). O método K-NN proposto pelos autores mostrou-se superior aos convencionais, considerando-se sua complexibilidade computacional.

Também em 1999, Kinoshita et al. [KINOSHITA et al. (1999)], apresentaram um estudo de classificação de nódulos em mamogramas digitalizados por meio de ANN. O algoritmo de treinamento "backpropagation" foi usado para ajustar os pesos da ANN. Foram investigados 28 atributos (14 de forma e 14 de textura). Atributos de textura foram calculados utilizando os analisadores propostos por Haralick et al. [HARALICK et al. (1973)]. O melhor resultado apresentado pelos autores é para utilização de ANN com 5 camadas gerando $92.6 \%$ de especificidade e $94 \%$ de sensibilidade, concluindo que atributos de textura e de forma demonstram uma alta discriminação na caracterização de nódulos em mamografias.

Um estudo semelhante foi realizado por Ferrari et al. [FERRARI et al. (1999)], porém aplicado à classificação de microcalcificações. Os autores utilizaram atributos de forma, extraído de microcalcificações e contraste e atributos de textura, extraídos das ROIs, para classificação precoce de lesões de mama com microcalcificações associadas. Esses atributos foram analisados utilizando três classificadores estatísticos: dois classificadores paramétricos (linear (LC), e quadrático (QC)); e um método não paramétrico ("K-Nearest Neighbor" (K-NN)), no qual a decisão é realizada através da verificação dos rótulos dos K-vizinhos mais próximos. Os autores apresentaram o melhor resultado sendo para o classificador LC, com $95 \%$ de sensibilidade e $68 \%$ de especificidade, seguido pelo classificador K-NN com $82 \%$ de sensibilidade e $87 \%$ de especificidade e o 
classificador QC com $74 \%$ de sensibilidade e $93 \%$ de especificidade.

Também em 1999, Lin et al. [LIN et al. (1999)], propuseram um método para recuperação de imagens regulares em um banco de dados. Para isso são extraídos as primitivas de textura que caracterizam as propriedades de periodicidade da imagem. Depois disto cinco atributos de textura são computados da matriz SGLD, que caracterizam estatisticamente as propriedades correspondentes à imagem. Segundo os autores os atributos escolhidos foram considerados mais discriminantes entre os sugeridos por Haralick et al. [HARALICK et al. (1973)], sendo eles: Energia, Entropia, Correlação, MDI e Inércia. Os autores concluíram que, os atributos de textura são satisfatórios para descrição de propriedades estatísticas e demonstraram-se insensíveis a translação e rotação das imagens.

Em 1999, Tourassi et al. [TOURASSI (1999)], destacam os métodos de análise de imagem por textura e seu grande desenvolvimento e utilização na área de imagens médicas, dado o grande interesse nos sistemas CAD. Segundo o autor, os sistemas CAD vem de modo a proporcionar aos radiologistas um aumento na habilidade visual, com o uso de atributos extraídos da imagem, podendo ser relevantes no diagnóstico do problema e melhorando a performance do médico quando utilizados como segunda opinião.

Também em 1999, Qi e Snyder [QI \& SNYDER (1999)], propõem o conceito de "Content-Based Image Retrieval" (CBIR), que consiste basicamente de duas etapas: criação do índice e recuperação da imagem. Os autores demonstram o potencial de sua aplicação em "Picture Archival and Communication System" (PACS), utilizando como exemplo uma base de dados de ROIs extraídas de mamogramas digitais. A criação do índice deriva das informações das componentes de forma da lesão suspeita, que é segmentada baseada no maior valor local do histograma. A informação de forma do objeto é caracterizada pelo valor de 2 componentes: raiz quadrada do valor da matriz de dispersão e histograma de forma projetado nessa componente. Uma forma circular ou oval possui projeção próxima a uma distribuição gaussiana, já uma forma irregular não 
se aproxima de uma distribuição gaussiana. O vetor de características para qualquer imagem apresenta 3 componentes (primeiro componente, segundo componente e valor de aproximação da gaussiana). Para realizar uma consulta, a imagem de entrada tem os valores das componentes e da gaussiana computados, sendo o seu vetor de características comparado com os vetores das imagens armazenadas.

Em 2000, Mudigonda et al. [MUDIGONDA et al. (2000)], desenvolveram um sistema CAD para classificação de massas em mamogramas como malignos ou benignos. Neste estudo os autores utilizaram de atributos de gradiente e textura, para avaliar a eficácia de informações de texturas processadas nas regiões de massas em comparação com as informações de texturas presentes nas margens das massas. Para tanto, foram utilizado um modelo poligonal para extração de uma faixa de "pixels" nas margens das massas, 5 atributos de textura propostos por Haralick et al [HARALICK et al. (1973)] (Entropia, Correlação, Energia, MDI e Variância da Diferença) e duas medidas de gradiente (Direção e Variação). Os autores concluíram em seus estudos que a análise de textura nas margens de massas é discriminante para massas benignas e tumores malignos com uma área $(\mathrm{A} z=0.85)$ na curva $\mathrm{ROC}$ na melhor classificação.

Em 2000, Takahashi et al. [TAKAHASHI et al. (2000)], desenvolveram um sistema automatizado para extração de atributos da imagem, podendo ser utilizado para indexação e recuperação de imagens. Para isso utilizaram dois atributos espaciais sendo eles borda e textura. Para extração de atributos de textura foi adotado pelos autores a matriz SGLD e utilizados sete descritores estatísticos (Contraste, Correlação, MDI, Variância da Diferença, Diferença da Entropia e dois tipos de informação de correlação). A precisão do sistema foi comparada com o julgamento humano. Os autores concluíram que os atributos espaciais (texturas e bordas), informam a estrutura de uma imagem e podem ser utilizados em sistemas de recuperação de imagens.

Também em 2000, Vince et al. [VINCE et al. (2000)], realizaram um estudo comparativo de cinco métodos de análise de textura para caracterização de plaquetas coronárias em imagens de ultra-som intravascular, técnica de diagnóstico por imagem que 
proporciona uma visualização tomográfica das artérias. Os autores testaram os seguintes métodos: Histograma de primeira ordem, Haralick, Laws, Matriz de diferença de níveis de cinza vizinhos e Espectro de textura. A auto-avaliação realizada pelos autores demonstrou os melhores resultados para os métodos propostos por Haralick, tendo como destaque os atributos de Entropia e MDI. 


\section{Capítulo 4}

\section{Caracterização de imagens}

\section{mamográficas}

A mamografia ainda é considerada o método mais eficaz para a deteç̧ão precoce do câncer de mama, permitindo tanto a identificação do tumor quando ainda não é palpável bem como a deteç̧ão de agrupamentos de microcalcificações [MORROW et al. (1992)], [LEFEBVRE et al. (1994)], [PETRICK et al. (1996)] e [GIGER (1999)]. O posicionamento preciso e cuidadoso da mama durante a mamografia é um requisito fundamental no diagnóstico [BONTRAGER (1999)].

A imagem mamográfica deve demonstrar a quantidade máxima de tecido mamário em cada imagem, contraste máximo, resolução excelente e não conter artefatos. Para tanto, deve ser obtido em um aparelho dedicado de raios $\mathrm{X}$ e os écrans, chassis e processadoras devem estar em condições ótimas e serem monitorados regularmente através de um controle de qualidade [BONTRAGER (1999)].

\subsection{Anatomia da mama}

Na mulher adulta, a glândula mamária, ou mama, é uma saliência cônica ou hemisférica localizada na parede torácica anterior e lateral. Há grande variação no seu tamanho de 
um indivíduo para outro e até mesmo na mesma mulher, dependendo da sua idade e da influência de vários hormônios. Entretanto, a mama normalmente estende-se da porção anterior da segunda costela até a sexta ou sétima costela, e da borda lateral do esterno até a axila [BONTRAGER (1999)].

\subsubsection{Anatomia da superfície}

A anatomia da superfície inclui o mamilo, uma pequena projeção que contém uma coleção de aberturas de ductos provenientes das glândulas secretoras no interior do tecido mamário. A área pigmentada que circunda o mamilo é denominada aréola, definida como uma área circular de cor diferente que circunda um ponto central. A junção da parte inferior da mama com a parede inferior do tórax é chamada de prega inframamária. O prolongamento axilar é uma faixa de tecido que envolve o músculo peitoral lateralmente (Figura 4.1) [BONTRAGER (1999)].

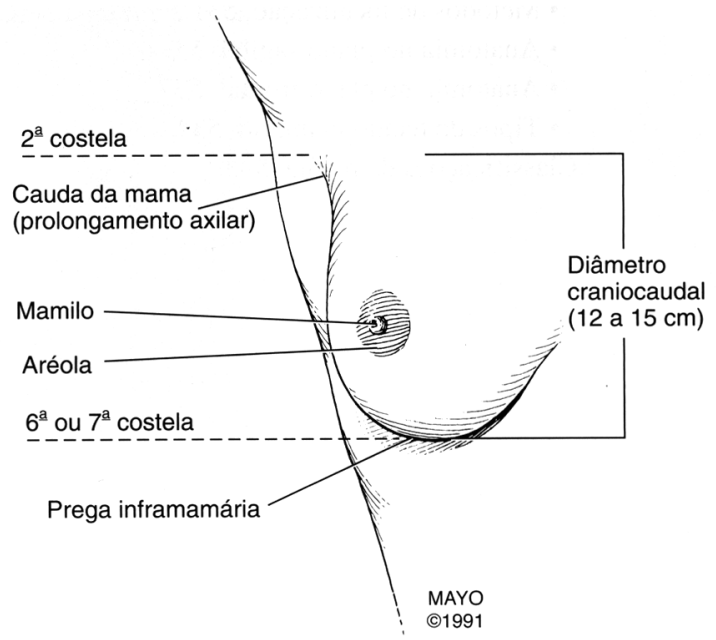

Figura 4.1: Anatomia superficial

A largura da mama na maioria das pacientes é maior que a medida vertical, do topo à parte inferior. A medida vertical, que pode ser descrita como o diâmetro craniocaudal, é, em média, de 12 a $15 \mathrm{~cm}$ na parede torácica. Há tecido mamário sobre as cartilagens costais próximo ao esterno e tecido mamário que vai até a axila. O tecido mamário 
que chega até a axila é denominado cauda da mama ou prolongamento axilar da mama [BONTRAGER (1999)].

\subsubsection{Anatomia no plano sagital}

Um plano sagital através da mama é ilustrado na figura 4.2, que mostra a relação entre a glândula mamária e as estruturas subjacentes da parede torácica. Neste desenho a prega inframamária está ao nível da sexta costela, mas existe grande variação entre os indivíduos [BONTRAGER (1999)].

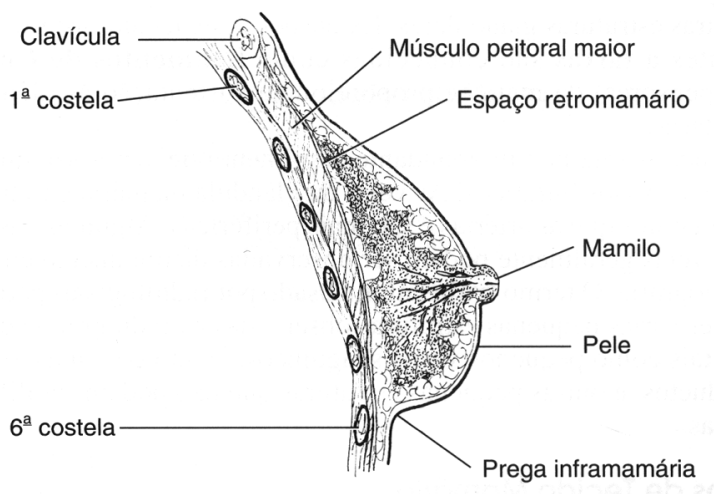

Figura 4.2: Corte sagital da mama

O músculo peitoral maior é observado sobre a caixa torácica. Um folheto de tecido fibroso circunda a mama abaixo da superfície cutânea. Um folheto semelhante de tecido recobre o músculo peitoral maior. Estes dois folhetos fibrosos conectam-se em uma área denominada espaço retromamário. Como as conexões dentro do espaço retromamário são bastante frouxas, a mama normal apresenta considerável mobilidade sobre a parede torácica [BONTRAGER (1999)].

A posição do tecido glandular em relação ao tecido adiposo é ilustrada na figura 4.3. A porção central da mama é constituída basicamente de tecido glandular. Quantidades variáveis de tecido adiposo ou gorduroso circundam o glandular. A variação de tamanho de uma pessoa para outra é devida basicamente à quantidade de tecido adiposo na mama. A quantidade de tecido glandular é bastante constante entre as mulheres 
[BONTRAGER (1999)].

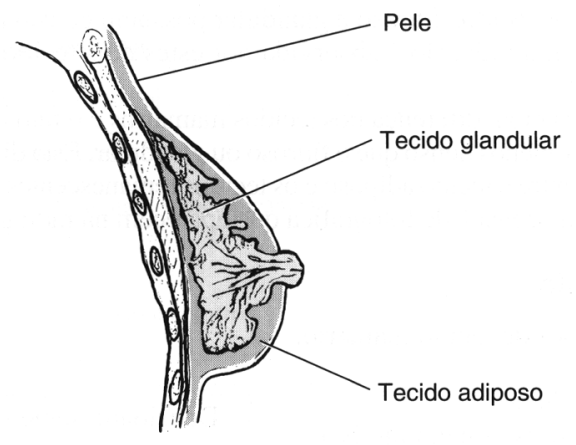

Figura 4.3: Corte sagital da mama

\subsubsection{Anatomia no plano frontal}

O tecido glandular da mama é dividido em 15 ou 20 lobos dispostos como os raios de uma roda circundando o mamilo (Figura 4.4) [BONTRAGER (1999)].

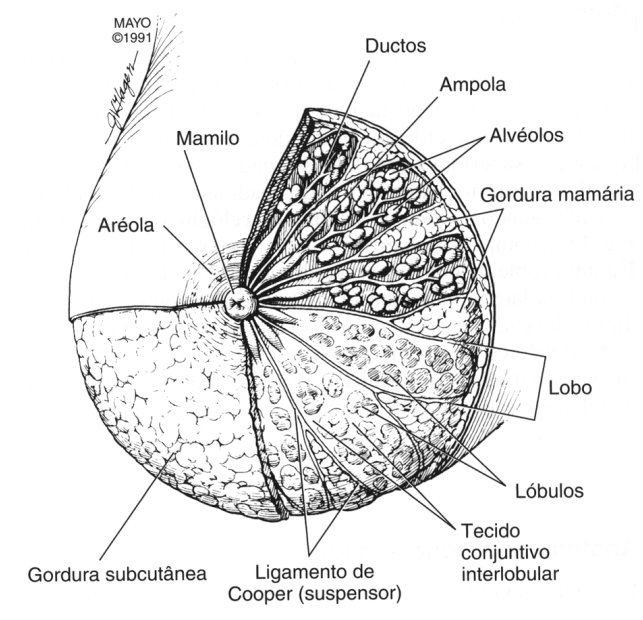

Figura 4.4: Mama - vista anterior

Os lobos glandulares, constituídos de vários lóbulos individuais, não são claramente separados, mas reunidos num arranjo radial como mostrado na figura 4.4. Distalmente, os lóbulos menores constituem em grupos de alvéolos arredondados. Os grupos de alvéolos que formam os lóbulos são interconectados e drenam por ductos individuais. Cada ducto aumenta formando uma pequena ampola que serve como um reservatório 
para o leite logo antes de terminar em uma pequena abertura na superfície do mamilo [BONTRAGER (1999)].

As várias subdivisões destes ductos e das ampolas associadas são ativadas durante a gravidez, a fim de preparar para a lactação, e após o parto, no intuito de produzir leite pra o recém-nascido [BONTRAGER (1999)].

Uma camada de tecido adiposo imediatamente sob a pele, circunda e recobre o tecido glandular. O tecido adiposo mamário lobular, gordura subcutânea, é interposto aos elementos glandulares. Tecidos conjuntivos interlobular ou fibroso circundam e sustentam os lobos e outras estruturas glandulares. Extensões deste tecido fibroso semelhantes a faixas são conhecidas como ligamentos de Cooper (suspensores) da mama e proporcionam sustentação às glândulas mamárias [BONTRAGER (1999)].

Cada mama possui abundante suprimento de vasos sanguíneos, nervos e vasos linfáticos. As veias da glândula mamária geralmente são maiores que as artérias e são muito periféricas. Algumas das maiores veias geralmente podem ser observados distintamente em uma mamografia. O termo trabéculas é usado por radiologistas para descrever várias pequenas estruturas observadas na radiografia, tais como pequenos vasos sanguíneos, tecido conjuntivo fibroso, ductos, e outras pequenas estruturas que não podem ser diferenciadas [BONTRAGER (1999)].

\subsection{Tipos de tecido mamário}

Um dos principais problemas em radiografia da mama é que os vários tecidos possuem contraste inerente muito baixo. O tecido mamário pode ser dividido em três tipos principais: (1) glandular, (2) fibroso ou conjuntivo e (3) adiposo (Figura 4.5). Como estes são todos tecidos moles, não há osso ou tecido cheio de ar para produzir contraste. Os tecidos fibrosos e glandular possuem densidade semelhante - isto é, a radiação é absorvida por este dois tecidos de forma semelhante [BONTRAGER (1999)].

A principal diferença nos tecidos mamários é o fato de o tecido adiposo ser menos 


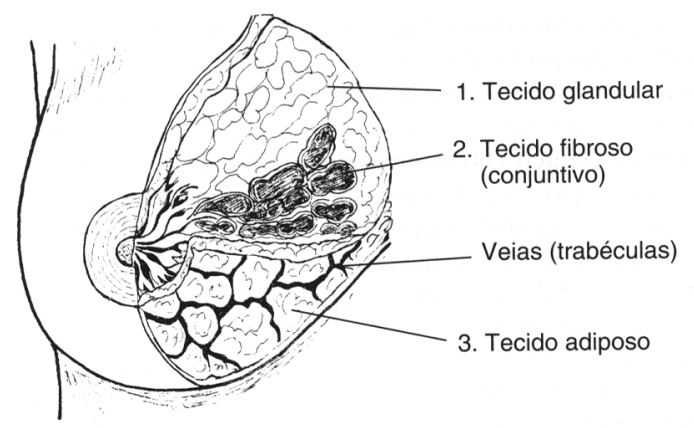

Figura 4.5: Mama - vista anterior (três tipos de tecidos)

denso que o fibroso ou glandular. Esta distinção na densidade entre o tecido adiposo e os tecidos remanescentes produz as diferenças da densidade fotográfica que aparecem na radiografia [BONTRAGER (1999)].

A mamografia (Figura 4.6) mostra diferenças nas densidades dos tecidos. Esta diferenças são a base da imagem radiológica da mama. Pode-se observar que os tecidos glandular e fibroso ou conjuntivo mais densos apresentam-se como estruturas ou regiões claras. Os tecidos adiposos menos densos apresentam-se cinza-claros a cinza-escuros, dependendo da sua espessura [BONTRAGER (1999)].

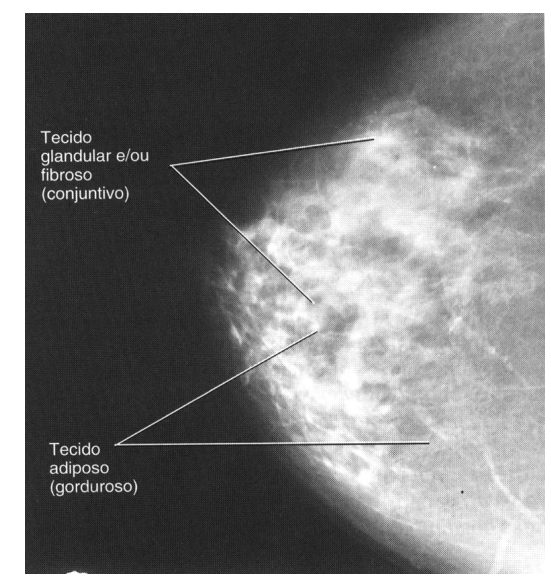

Figura 4.6: Mamografia 


\subsection{Métodos de localização}

Dois métodos são comumente usados para subdividir a mama em áreas menores para fins de localização. O sistema de quadrante, apresentado na figura 4.7, é o mais fácil de ser utilizado. Podem ser descritos quatro quadrantes que utilizam o mamilo como o centro. São eles: QSE (quadrante superior externo), QSI ( quadrante superior interno), QIE (quadrante inferior externo) e QII (quadrante inferior interno) [BONTRAGER (1999)].

Um segundo método, o sistema de relógio, também mostrado na figura 4.7 a direita, compara a superfície da mama ao mostrador de um relógio. Há um problema com este método quando se descreve uma porção medial ou lateral da mama. A parte descrita como 3 horas na mama direita deve ser descrita como 9 horas na esquerda [BONTRAGER (1999)].

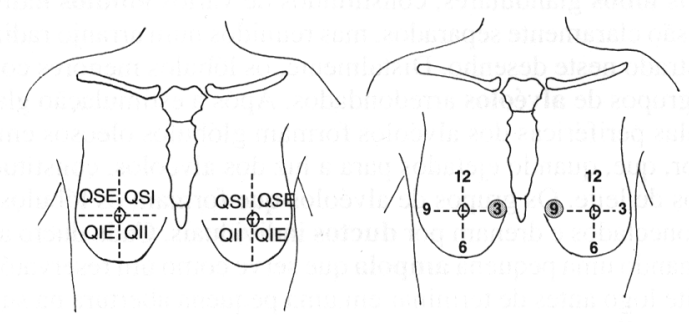

Figura 4.7: Localização da mama - sistema de quadrantes e do relógio

\subsection{Terminologia e abreviações}

Determinados termos sobre posicionamento, alguns dos quais são exclusivos da mamografia, precisam ser compreendidos e usados corretamente. Estes termos com suas abreviações (Tabela 4.1) são usados para identificar filmes e são nomenclaturas aprovadas pelo Colégio Americano de Radiologia (CAR) em outubro de 1995 [BONTRAGER (1999)]. 


\begin{tabular}{|l|l|}
\hline Nomenclatura & Descrição \\
\hline \hline CC & Craniocaudal \\
\hline MLO & Oblíqua mediolateral \\
\hline CCLE & Craniocaudal lateralmente exagerada \\
\hline ML & Mediolateral \\
\hline LM & Lateromedial \\
\hline ID & Implante deslocado \\
\hline VA & Vista axilar \\
\hline VC & Vista de clivagem \\
\hline CA & Vista de cauda axilar \\
\hline OLM & Inferolateral-superomedial \\
\hline OSI & Oblíqua superolateral-inferomedial \\
\hline TAN & Tangencial \\
\hline LR $\dagger$ & Lateral deitada \\
\hline ML $\dagger$ & Medial deitada \\
\hline DB & Caudocranial de baixo \\
\hline
\end{tabular}

Tabela 4.1: Terminologia e abreviações da mamografia

\subsection{Posicionamento da mama}

A grande variabilidade da mama, com relação à proporção de tecido adiposo e tecido fibroglandular, produz algumas dificuldades técnicas na realização de uma mamografia de boa qualidade [BONTRAGER (1999)]

A base da mama é aquela parte próxima da parede torácica, enquanto a área próxima do mamilo é denominada ápice. Nas incidências craniocaudal ou mediolateral, a base da mama é muito mais espessa e contém tecidos muito mais densos que o ápice [BONTRAGER (1999)].

Para superar esta diferença anatômica, é utilizada compressão em combinação com um cone de formato especial, de forma que a porção central mais intensa do feixe de raios $\mathrm{X}$ penetre na base da mama, que é mais espessa (Figura 4.8)[BONTRAGER (1999)].

\subsubsection{Tubo de raios $\mathrm{X}$}

O aspecto mais distinto do aparelho de mamografia é o desenho peculiar do tubo de raios $\mathrm{X}$, que tem um alvo de molibdênio (em alguns aparelhos o alvo utilizado pode ser de molibdênio ou ródio, isto para amenizar as diferenças de densidades) com pequenos 
pontos focais de 0.3 e $0.1 \mathrm{~mm}$. A configuração anódica produz um efeito anódico proeminente devido à curta distância foco-filme (DFoFi), e o uso de um pequeno ânguloalvo de referência. Como o tubo de raios $\mathrm{X}$ está alinhado com o catodo colocado sobre a base da mama (na parede torácica) e o anodo externamente em direção ao ápice (área mamilar), felizmente o efeito anódico pode ser usado para produção de uma imagem com densidades mais uniforme [BONTRAGER (1999)].

Grades anti-espalhamento são comumente usadas na maioria das mamografias, juntamente com controle de exposição automático e dispositivo de compressão da mama [BONTRAGER (1999)].

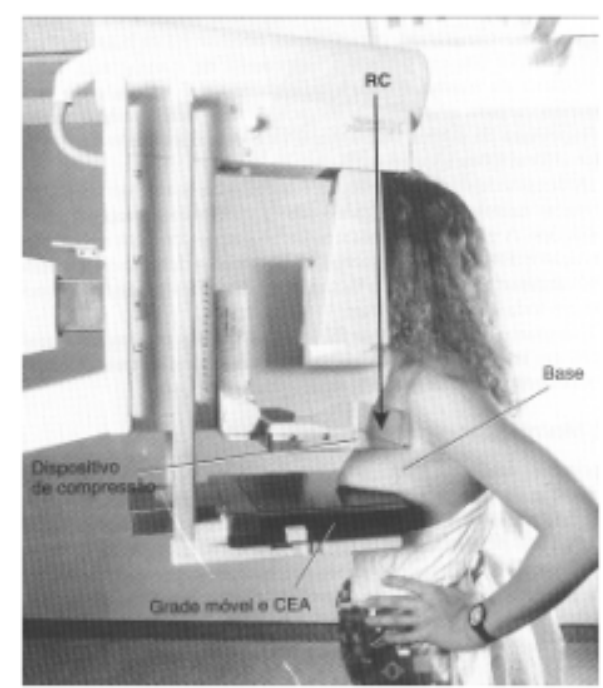

Figura 4.8: Posicionamento de paciente

\subsubsection{Compressão}

Todos os aparelhos de mamografia contém um dispositivo de compressão usados para comprimir a mama. Aperfeiçoamentos na tecnologia de compressão da mama nos últimos anos aumentaram muito a visibilidade de detalhes nas imagens. $\mathrm{O}$ dispositivo de compressão é feito de um plástico que permite inclusive a transmissão dos raios $\mathrm{X}$ de baixa energia. O dispositivo deve ter uma borda da parede torácica reta para permitir que a compressão apreenda os tecidos mamários próximos da parede torácica. Na com- 
pressão são tipicamente aplicados de 11,3 a 18,1 Kgf de pressão [BONTRAGER (1999)].

A compressão apropriada aplicada é um dos componentes fundamentais na produção da mamografia de alta qualidade. Os objetivos da compressão são: (1) diminuir a espessura da mama, (2) colocar as estruturas da mama o mais próximo possível do filme e (3) igualar a densidade radiográfica entre a base e o ápice. Estes dois fatores melhoram a qualidade da imagem mediante redução da dispersão e também por redução da ampliação de estruturas mamárias. Isso é ilustrado ao se compararem os desenhos não comprimidos e comprimidos (Figura 4.9). Observar a localização das microcalcificações e a da lesão que estão circundadas por tecido mamário denso no desenho A, e como a compressão as aproximou do filme (desenho B). Portanto, a espessura geral da mama também foi muito reduzida, o que diminui pela metade a dispersão para o raio da radiação primária [BONTRAGER (1999)].

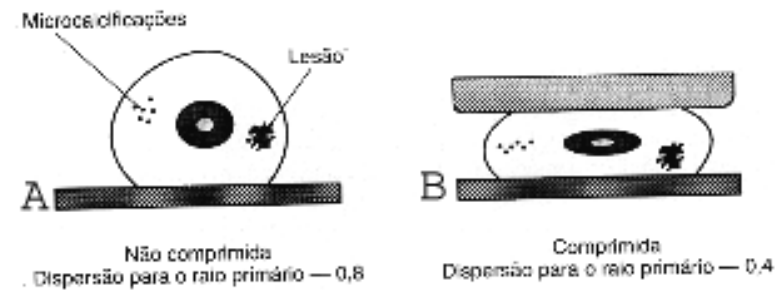

Figura 4.9: Efeito da compressão da mama

\subsubsection{Ampliação}

O método de ampliação é usado a fim de aumentar áreas específicas de interesse como pequenas lesões ou microcalcificações. Isso requer um tubo de raio $\mathrm{X}$ com um ponto focal de $0,1 \mathrm{~mm}$ para manter a resolução da imagem. Aumentos de 1,5 a 2 vezes podem ser usados por inserção de uma plataforma de ampliação entre o filme e a mama (Figura 4.10). Esta técnica de ampliação pode ser usada na maioria das incidências utilizadas na mamografia [BONTRAGER (1999)]. 


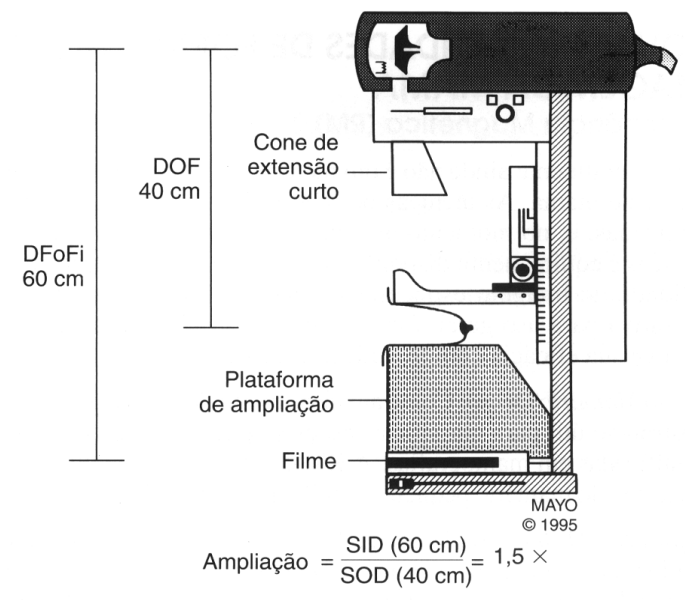

Figura 4.10: Ampliação da mama

\subsubsection{Dose para a paciente}

A dose absorvida pela paciente é significativa na mamografia. Uma dose glandular média absorvida pela paciente para uma projeção crânio-caudal é de 3 mGy (para uma mama comprimida de $4.5 \mathrm{~cm}$ constituída de $50 \%$ de tecido glandular e $50 \%$ de tecido adiposo, para sistemas tela/filme, com grade e unidades mamográficas dedicadas com alvo de Mo). Por exemplo, uma incidência de tórax posterior-anterior, teria uma absorção de 0.4 mGy [SCHILDT (1998)]. A razão da dose relativamente alta para a mamografia é a kVp muito baixa (25 a 28) e o mAs alto (75 a 85) necessários [BONTRAGER (1999)].

A principal forma de reduzir a dose para a paciente é através do posicionamento cuidadoso e preciso, o que minimiza a necessidade de repetições, que deve ser menor que 5\%, segundo recomendações do CAR [BONTRAGER (1999)].

\subsection{Incidências}

\subsubsection{Craniocaudal (CC)}

Demonstra bem todo o tecido mamário e as mamas são geralmente mostradas em filmes separados para comparação (Figura 4.11)[BONTRAGER (1999)]. 

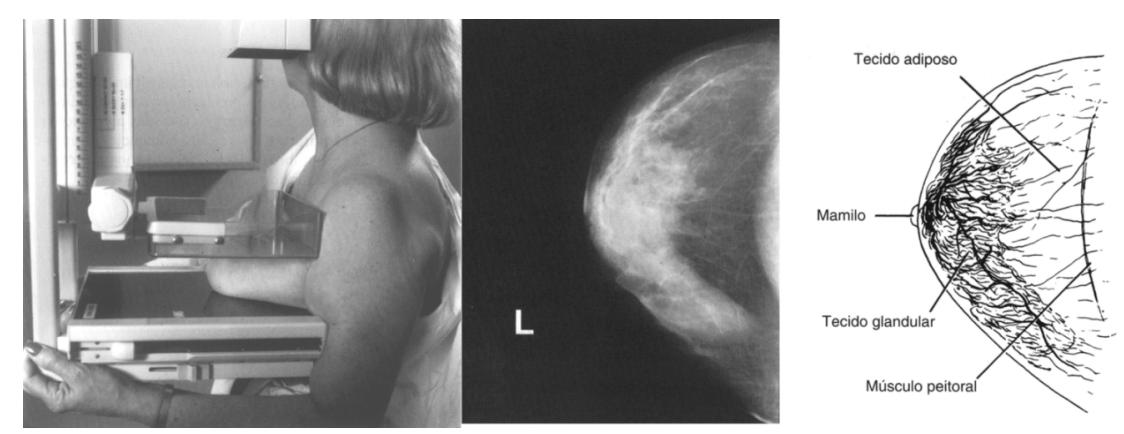

Figura 4.11: Incidência CC

\subsubsection{Oblíqua mediolateral (MLO)}

Demonstra bem todo o tecido mamário e as mamas são geralmente mostradas em filmes separados para comparação (Figura 4.12)[BONTRAGER (1999)].
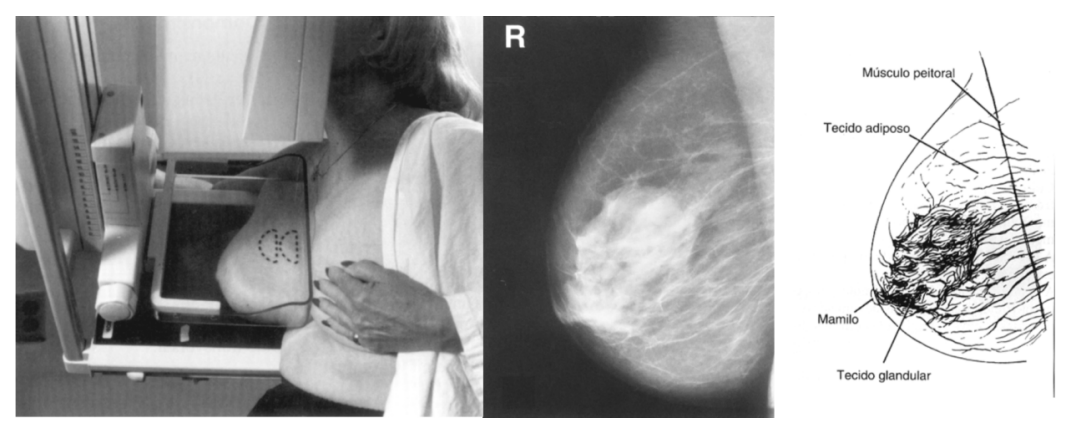

Figura 4.12: Incidência MLO

\subsubsection{Craniocaudal lateralmente exagerada (CCLE)}

Demonstra bem todo o tecido mamário com ênfase do tecido axilar, é uma incidência opcional solicitada com maior freqüência (Figura 4.13). É realizada se a CC não mostra todo o tecido axilar. Além disso, geralmente é solicitada quando uma lesão é identificada na MLO e não é vista na CC [BONTRAGER (1999)].

\subsubsection{Mediolateral (ML) - incidência lateral verdadeira}

Demonstra bem estruturas de leite de cálcio (processo inflamatório da mama), pode ser solicitada pelo radiologista como opcional para verificar se uma anormalidade é real 

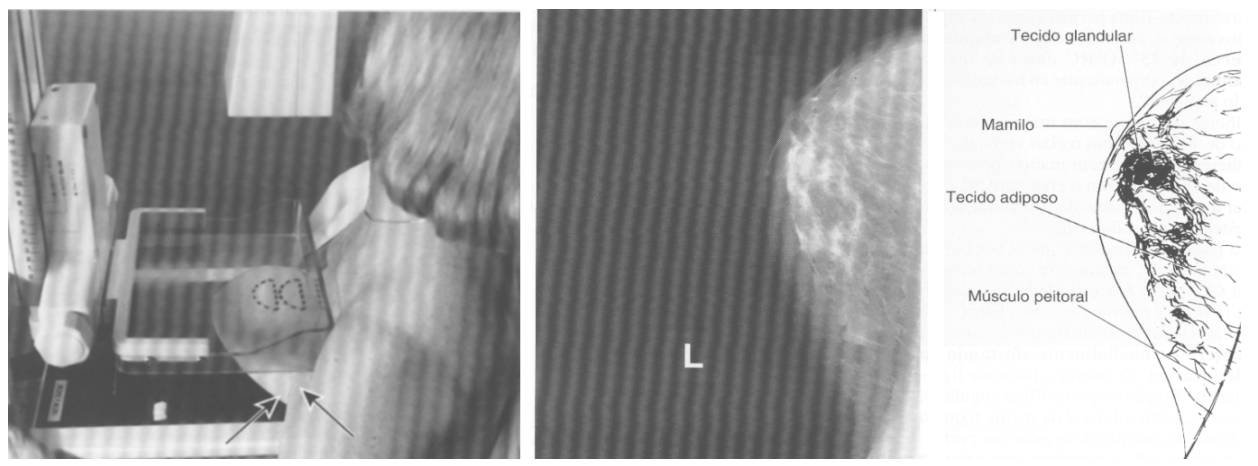

Figura 4.13: Incidência CCLE

quando observada apenas na MLO (Figura 4.14) [BONTRAGER (1999)].
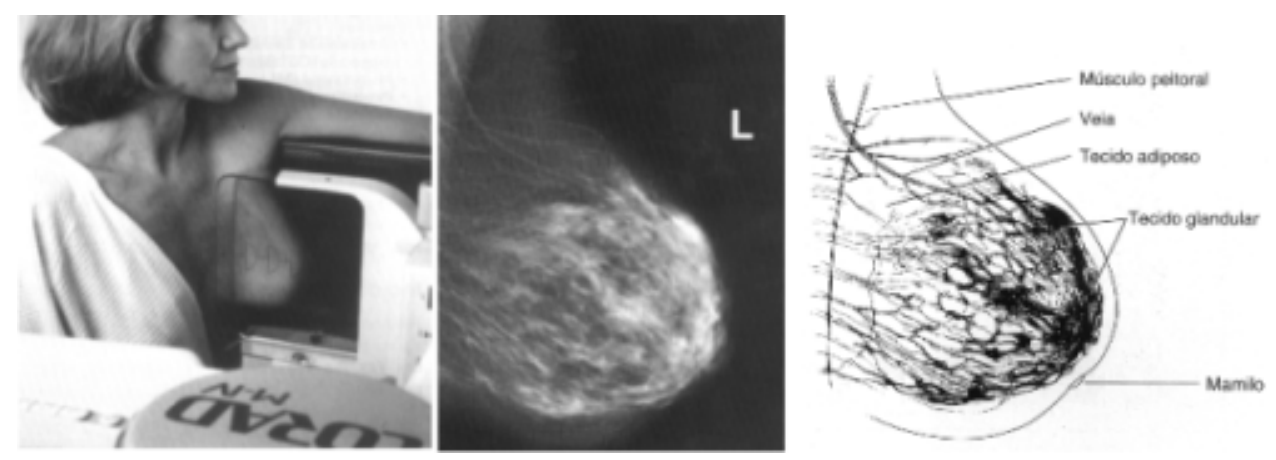

Figura 4.14: Incidência ML

\subsection{Classificação da mama}

A densidade relativa da mama é afetada basicamente pelas características mamárias inerentes da paciente, estado hormonal, idade e gestações. A glândula mamária sofre alterações cíclicas associadas à elevação e diminuição das secreções hormonais durante o ciclo menstrual, durante a gravidez e a lactação, e alterações graduais que ocorrem em toda a vida da mulher [BONTRAGER (1999)]. Entretanto, genericamente falando, as mamas podem ser classificadas em três grandes categorias, dependendo das quantidades de tecido fibroglandular em relação ao tecido adiposo [BONTRAGER (1999)].

1. Mama fibroglandular: a mama jovem geralmente é muito densa, pois contém 
quantidade relativamente pequena de tecido adiposo. A faixa etária comum para a categoria fibroglandular varia da pós-puberdade até cerca de trinta anos. Entretanto, as mulheres com mais de 30 anos que nunca amamentaram provavelmente também pertencerão a este grupo geral. Mulheres grávidas ou lactantes de qualquer idade também são incluídas neste grupo porque possuem um tipo de mama muito densa [BONTRAGER (1999)].

2. Mama fibrogordurosa: à medida que a mulher envelhece e ocorrem mais alterações nos tecidos mamários, há uma mudança gradual da pequena quantidade de tecido adiposo para uma distribuição mais igual de tecido gorduroso e fibroglandular. Portanto, em um grupo que varia dos 30 aos 50 anos de idade, a mama não é tão densa quanto um grupo jovem. Radiologicamente, esta mama tem densidade média e requer menor exposição que a mama do tipo fibroglandular. Várias gestações na vida reprodutiva de uma mulher acelerarão a evolução de sua mama para esta categoria fibrogordurosa [BONTRAGER (1999)].

3. Mama gordurosa: ocorre após a menopausa, comumente a partir dos 50 anos de idade. Após a idade reprodutora da mulher, a maior parte do tecido glandular da mama sofre atrofia, sendo convertido em tecido adiposo em um processo denominado involução. É necessária uma exposição ainda menor neste tipo de mama que nos primeiros dois tipos.

\subsection{Principais indicadores de lesões de mama}

Segundo Richardson et al. [RICHARDSON (1995)], os radiologistas utilizam-se de características de dois sinais principais para a discriminação entre tecidos normais e lesados. O primeiro sinal é a massa, nódulo ou neoplasma, sendo analisadas a forma e a densidade radiográfica. O neoplasma benigno possui bordas mais suaves enquanto a malignidade é caracterizada pela borda irregular (forma espicular).

O segundo sinal é a microcalcificação, caracterizada, segun- 
do Egan et al. [EGAN et al. (1980)] e Woods et al. [WOODS et al. (1994)], por depósito de cálcio de formatos e tamanhos variados.

Embora, os nódulos e as microcalcificações sejam os sinais mais comuns apresentados por lesões de mama, existem ainda muitos outros indicadores, como distorções do parenquima mamário, assimetria entre as mamas esquerda e direita e enrugamento de pele da mama. De acordo com Davies e Dance [DAVIES \& DANCE (1990)] e Giger [GIGER (1999)], aproximadamente 50\% dos carcinomas possuem microcalcificações associadas visíveis no mamograma e entre 50 e $80 \%$ dos carcinomas de mama revelam microcalcificações sob exame histopatológico.

\subsection{Padrão BI-RADS}

O padrão BI-RADS é produto de um trabalho conjunto entre vários membros do Colégio Americano de Radiologia em colaboração com o Instituto Nacional do Câncer, Centro de Prevenção e Controle de Doenças, Administração de Alimentos e Medicamentos (FDA "Food and Drug Administration"), Associação Médica Americana, Colégio Americano de Cirurgiões e Colégio Americano de Patologistas [BI-RADS (1998)].

No BI-RADS, a classificação dos achados radiológicos segue o seguinte padrão:

- Classificação 0 - Achados que necessitam de avaliação adicional.

- Classificação I - Negativo.

- Classificação II - Achado Benigno.

- Classificação III - Achado Provavelmente Benigno.

- Classificação IV - Achado Suspeito para Malignidade.

- Classificação V - Achado Altamente Suspeito para Malignidade. 


\subsubsection{Classificação dos nódulos mamários:}

Classificação I - nenhum nódulo é visualizado [BAUAB et al. (1999)].

Classificação II - nenhum nódulo suspeito é encontrado. Não requer seguimento especial. Exemplos: nódulos contendo gordura (linfonodo intramamário, hamartoma ou fibroadenolipoma, cisto oleoso; galactocele); fibroadenoma calcificado; prótese mamaria. Entram nessa classificação nódulos múltiplos ou únicos que avaliados ao ultra-som, demonstraram ser cistos simples. Antes da avaliação ecográfica, é preferencial deixá-los não classificados, sugerindo a avaliação adicional por ultrasom. Por isso da classificação 0, que consta do BI-RADS, representando achados que necessitem avaliação adicional [BAUAB et al. (1999)].

Obs.: Para nódulos com classificação III e IV, assim como para os acima descritos, a avaliação ultra-sonográfica do nódulo deve ser feita antes de se proceder à classificação [BAUAB et al. (1999)].

Classificação III - nódulo sólido, circunscrito, não calcificado, com forma esférica, oval ou macrolobulada. Apresentar características ecográficas sugestivas de lesão sólida provavelmente benigna, como forma elipsóide, halo ecogênico, reforço acústico posterior e ecotextura homogênea. Recomenda-se o seguimento a cada 6 meses, por 2 anos. Em mulheres de 35 a 40 anos que apresentam uma lesão sólida com características ecográficas que fujam do padrão típico de fibroadenoma, e sendo uma lesão não calcificada e com mais de $1 \mathrm{~cm}$ já no primeiro exame, a biópsia é recomendada, visto que o tempo de duplicação celular é mais curto na mulher mais jovem [BAUAB et al. (1999)] e [BAUAB (2000)].

Classificação IV - (1) nódulo sólido, esférico, oval ou macrolobulado com calcificações associadas, algumas irregularidades das margens, microlobulação e/ou mais de $25 \%$ de suas margens obscurecidas; (2) algumas das lesões classificadas ecograficamente como indeterminadas ou intermediárias: nódulos intracísticos, cistos com 
septações espessas; (3) nódulos considerados suspeitos ao ultra som. A biópsia deve ser considerada podendo ser por via percutânea ou cirúrgica [BAUAB et al. (1999)].

Classificação V - nódulos irregulares, com espiculação, com ou sem calcificação, palpáveis ou não. O diagnóstico diferenciado inclui: carcinoma, cicatriz pós-cirúrgica, lesão esclerosante radial, seqüela de abscesso, hematoma, necrose gordurosa e qualquer processo que resultem em acentuada fibrose. Neste grupo a biópsia deve ser realizada, com chance de malignidade de mais de $80 \%$ [BAUAB et al. (1999)].

\subsubsection{Classificação das calcificações mamárias:}

- Calcificações: diâmetro $>0,5 \mathrm{~mm}$.

- Microcalcificações: diâmetro $<0,5 \mathrm{~mm}$.

Classificação I - nenhuma calcificação é encontrada [BAUAB et al. (1999)].

Classificação II - calcificações anelares e arteriais, calcificações "em pipoca", "leite de cálcio" em microcistos, múltiplas calcificações secretórias, calcificações cutâneas e calcificações em fios de sutura [BAUAB et al. (1999)].

Classificação III - o examinador deve estar bem consciente das características das microcalcificações, que devem ser: (1) redondas ou ovais, do mesmo tamanho, difusamente distribuídas; (2) se forem agrupadas deve apresentar delimitação arredondada sem nenhuma característica intermediária de morfologia ou distribuição; (3) conforme se tornam distribuídas mais segmentar, linear ou focal, mesmo com morfologia uniforme, não devem ser incluídas nesta categoria. Recomenda-se seguimento periódico em 6, 12, 24 e 36 meses [BAUAB et al. (1999)] e [BAUAB (2000)].

Classificação IV - (1) microcalcificações, mesmo com morfologia uniforme, que apresentem distribuição regional, segmentar, linear ou focal (a não ser que apresentem morfologia tipicamente benigna); (2) microcalcificações agrupadas onde alguma(s) 
apresenta(m) morfologia diferente das demais; (3) microcalcificações puntiformes de tamanho variado e agrupadas; (4) microcalcificações agrupadas que não estavam presente no exame anterior (a não ser que apresentem morfologia tipicamente benigna). Neste grupo a biópsia deve ser considerada, lembrando porém que a maioria das lesões será benigna [BAUAB et al. (1999)].

Classificação V - (1) microcalcificações lineares e vermiformes desenhando trajetos de ductos; (2) microcalcificações pleomórficas. A biópsia deve ser realizada, sendo a chance de malignidade em torno de 90 a 100\% [BAUAB et al. (1999)].

\subsubsection{Densidade assimétrica:}

Classificação III - Densidade focal assimétrica não palpável: discreta área de tecido com densidade de tecido fibroglandular, visibilizada em duas projeções ortogonais, com margens côncavas e/ou tecido adiposo de permeio [BAUAB et al. (1999)].

Classificação IV - Densidade focal assimétrica palpável [BAUAB et al. (1999)].

\subsubsection{Alteração arquitetural:}

Classificação III - Área sutil de alteração arquitetural sem área central densa, em local de biópsia prévia [BAUAB et al. (1999)].

Classificação V - Distorção do tecido fibroglandular em espículas finas, sem nódulos e sem história prévia de biópsia no local [BAUAB et al. (1999)].

\subsubsection{Ducto dilatado solitário:}

Classificação III - Ducto solitário dilatado não associado a fluxo papilar espontâneo [BAUAB et al. (1999)].

Classificação IV - Ducto solitário dilatado associado a fluxo papilar espontâneo. 
- Padrão de dilatação ductal em localização não subareolar, com calcificações de natureza intermediária ou com alterações de intervalo em relação ao exame anterior [BAUAB et al. (1999)].

\subsubsection{Adenopatia axilar:}

Linfonodos axilares aumentados de volume, sem tecido adiposo central, devem ser mencionados no laudo, mas não classificados, pois sua classificação por imagem não é confiável [BAUAB et al. (1999)].

Segundo Bauab et al. [BAUAB et al. (1999)] e Bauab [BAUAB (2000)], o padrão BIRADS foi indicado na Jornada Paulista de Radiologia de 1998 como modelo para classificação nos estudos da mama, visando a uniformização dos termos e padrões na caracterização dos achados mamográficos. 


\section{Capítulo 5}

\section{Bancos de dados}

Neste tópico é apresentada uma noção geral sobre os modelos utilizados na construção do banco de dados, sendo eles: modelo lógico de banco de dados (modelo Entidade Relacionamento), modelo para construção do projeto físico de banco de dados (modelo Relacional), técnicas de controle de dependência (normalização) e método de consultas (Álgebra Relacional).

\subsection{Introdução e conceitos gerais}

Um banco de dados pode ser definido como um conjunto de dados devidamente relacionados. E por dados podemos compreender como fatos conhecidos que podem ser armazenados e que possuem um significado implícito. Porém, o significado do termo Banco de Dados é mais restrito que simplesmente a definição dada acima. Um banco de dados possui as seguintes propriedades: um banco de dados é uma coleção lógica coerente de dados com um significado inerente (uma disposição desordenada dos dados não pode ser referenciada como um banco de dados); um banco de dados é projetado, construído e povoado com dados para um propósito específico (possuindo um conjunto pré definido de usuários e aplicações); e representa algum aspecto do mundo real (minimundo) [ELMASRI \& NAVATHE (1989)] e [KORTH \& SILBERSCHATZ (1994)]. 
Um banco de dados pode ser criado e mantido por um conjunto de aplicações desenvolvidas especialmente para esta tarefa ou por um Sistema Gerenciador de Banco de Dados (SGBD). Um SGBD permite ao usuário criar e manipular bancos de dados de propósito geral. O conjunto formado por um banco de dados mais aplicações que o manipulam é chamado de Sistema de Banco de Dados (SBD), representado na Figura 5.1.

Sistema de Banco de Dados

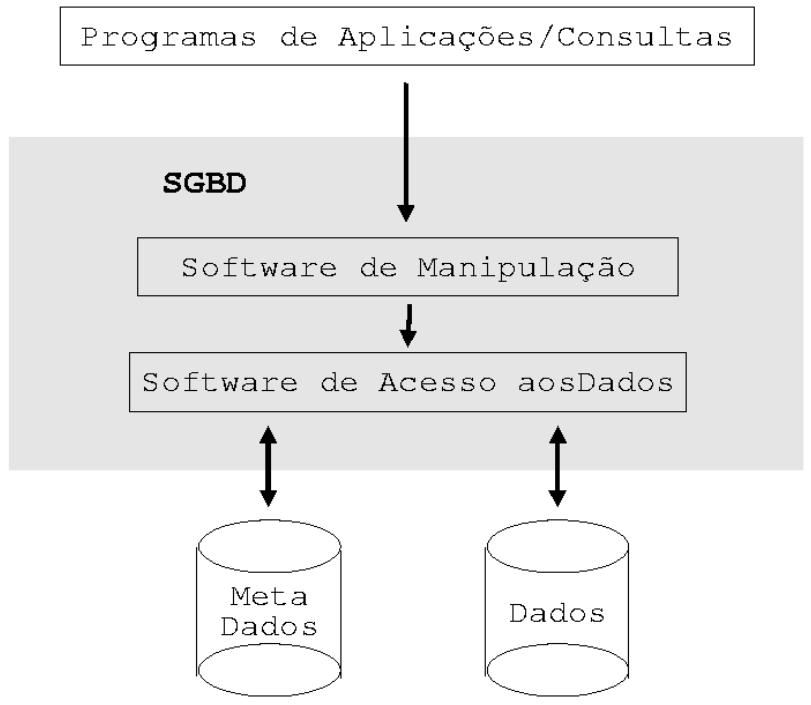

Figura 5.1: Ambiente de sistema de banco de dados

O SGBD mantém, além dos dados, as formas como são armazenados. Ou seja, contém uma descrição completa do banco de dados no catálogo do $S G B D$ que é chamada de Meta Dados.

\subsection{Modelo entidade relacionamento (ER)}

Modelo de dados conceitual de alto nível, utilizado principalmente durante o projeto do banco de dados, cujo princípio é estar o mais próximo possível da visão do usuário em relação aos dados, não se preocupando como estes dados são armazenados fisicamente 
[ELMASRI \& NAVATHE (1989)] e [KORTH \& SILBERSCHATZ (1994)].

\subsection{Modelo entidade relacionamento estendido}

O modelo Entidade Relacionamento Estendido (ERE), fornece uma semântica para a modelagem de informações mais complexas. O modelo ERE engloba todos os conceitos do modelo ER mais os conceitos de sub-classe, super-classe, generalização e especialização e o conceito de herança de atributos. Mesmo tratando classes e sub-classes, ele não possui a mesma semântica de um modelo orientado a objetos [ELMASRI \& NAVATHE (1989)] e [KORTH \& SILBERSCHATZ (1994)].

\subsection{Modelo relacional}

Tem a finalidade de representar os dados como uma coleção de relações, onde cada relação é representada por uma tabela. Quando uma relação é pensada como uma tabela de valores, cada linha nesta tabela representa uma coleção de dados relacionados. Estes valores podem ser interpretados como fatos descrevendo uma instância de uma entidade ou de um relacionamento. O nome da tabela e das colunas desta tabela são utilizados para facilitar a interpretação dos valores armazenados em cada uma das suas linhas. Todos os valores em uma coluna são necessariamente do mesmo tipo. Na terminologia do modelo relacional, cada tabela é chamada de relação; uma linha de uma relação é chamada de "tupla"; o nome de cada coluna é chamado de atributo; o tipo de dado que descreve cada coluna é chamado de domínio (figura 5.2) [ELMASRI \& NAVATHE (1989)] e [KORTH \& SILBERSCHATZ (1994)].

\subsection{Normalização}

Pode ser definido como processo de eliminação de esquemas de relações (tabelas) não satisfatórios, através de uma bateria de testes para certificar se o mesmo está na 


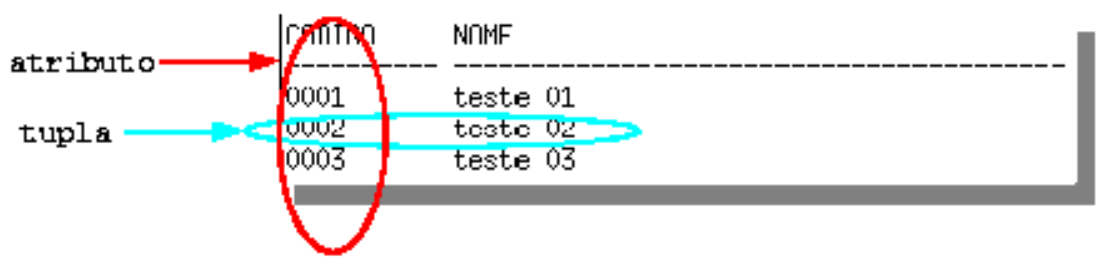

Figura 5.2: Descrição da tabela

$1^{\mathrm{a}}, \quad 2^{\mathrm{a}}$ e $3^{\mathrm{a}}$ Formas Normais $\quad$ [ELMASRI \& NAVATHE (1989)] e [KORTH \& SILBERSCHATZ (1994)].

A $1^{\text {a }}$ Forma Normal define que os atributos de uma tabela devam ser indivisíveis, ou seja, não são permitidos atributos multivalorados, compostos ou multivalorados compostos.

A $2^{\mathrm{a}}$ Forma Normal é definida pelo conceito da dependência funcional total. Uma dependência funcional X -> Y é total se removermos um atributo A qualquer do componente $\mathrm{X}$ e desta forma, a dependência funcional deixa de existir.

A $3^{\mathrm{a}}$ Forma Normal é definida pelo conceito de dependência transitiva. Uma dependência funcional $\mathrm{X}->\mathrm{Y}$ em uma tabela $\mathrm{T}$ é uma dependência transitiva se existir um conjunto de atributos $\mathrm{Z}$, que não é um subconjunto de chaves de $\mathrm{T}$ e as dependências $\mathrm{X}->\mathrm{Z}$ e Z $->\mathrm{Y}$ válidas.

\section{6 Álgebra relacional}

É definida como uma coleção de operações canônicas que são utilizadas para manipular as relações. Estas operações são utilizadas para selecionar tuplas de relações individuais ou para combinar "tuplas" de relações diferentes, sendo o resultado de cada operação uma nova relação, a qual também pode ser manipulada pela álgebra relacional [ELMASRI \& NAVATHE (1989)] e [KORTH \& SILBERSCHATZ (1994)]. 


\section{Capítulo 6}

\section{Materiais e métodos}

Neste capítulo são descritos os principais métodos e equipamentos empregados para a realização deste trabalho de mestrado. Apresentamos na figura 6.1 um diagrama exibindo a metodologia utilizada para realização da indexação e recuperação de imagens pelo conteúdo, utilizando atributos de textura sugeridos por Haralick et al. [HARALICK et al. (1973)].

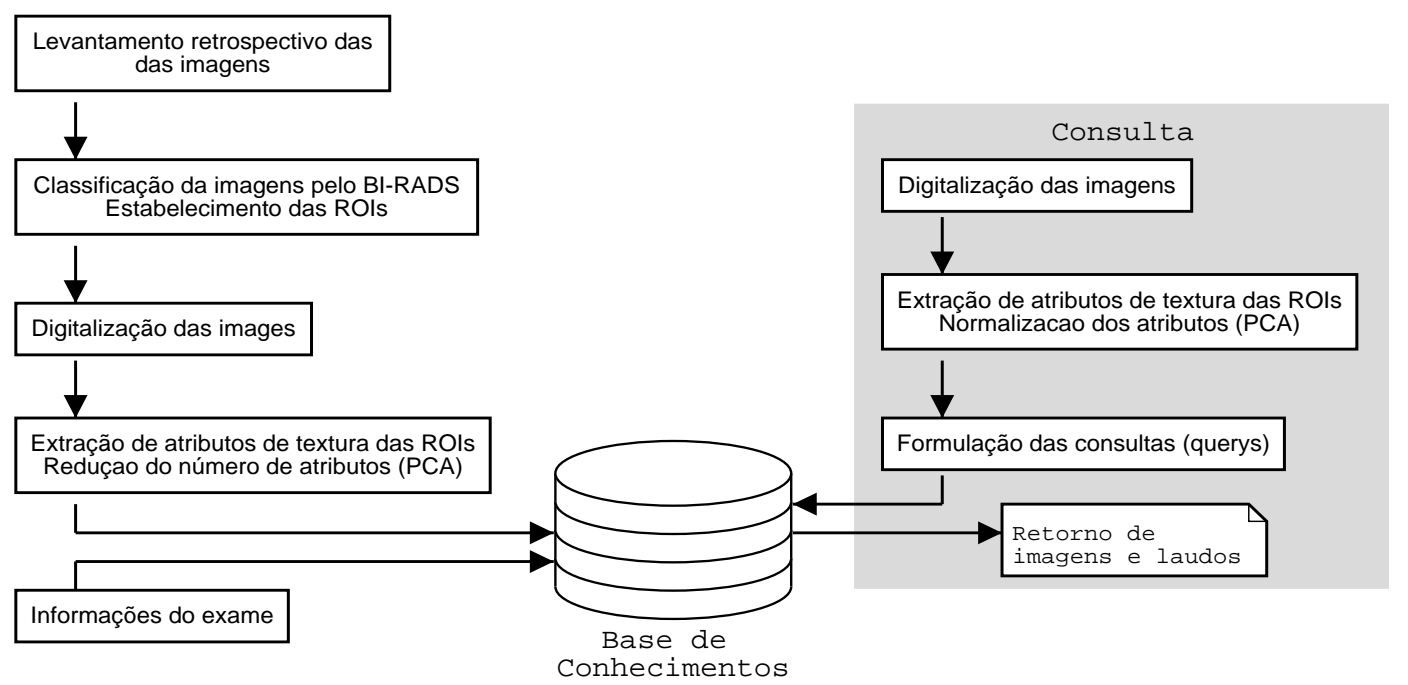

Figura 6.1: Diagrama de blocos representando o processo de indexação, armazenamento e recuperação de imagens 


\subsection{Sistema operacional}

Em acordo com a tendência local e também constatada em outros grupos de pesquisa em âmbito mundial, optou-se por um sistema operacional mais robusto e estável. O sistema operacional UNIX com suas estações de trabalho poderosas e amplamente divulgado no meio acadêmico, seria uma excelente plataforma para o desenvolvimento do projeto, porém seu custo é muito elevado.

A necessidade de uma plataforma que atendesse às necessidades de desempenho, estabilidade e não dependesse de um hardware específico levou ao sistema operacional LINUX. O LINUX é um sistema operacional derivado do UNIX, multiusuário, multiprocessado, multitarefa, seguro, escalonável e portável (disponível para X86, ou seja, Intel e compatíveis, Motorola 68K, Digital, Alpha, Sparc, Mips, PowerPC entre outros), possuindo interfaces gráficas e de livre distribuição. Sua implementação é compatível ao POSIX ("Portable Operating System Interface") e seu desenvolvimento feito sob o projeto GNU ("General Public License") da Fundação de Softwares Livres. Neste projeto foi utilizado o Red Hat 6.2, kernel 2.2.16-3.

\subsection{Linguagem de desenvolvimento}

Partindo do princípio que a linguagem de programação e desenvolvimento deva ser genérica, versátil e robusta, escolheu-se a linguagem C [SCHILDT (1998)].

Desse modo, todo o projeto foi desenvolvido em linguagem $\mathrm{C} / \mathrm{C}++$, desde a conexão com o banco de dados, o processamento das imagens para extração dos atributos de textura, visualização das imagens e interface com o usuário.

A interface com o usuário, em particular, deve ser de fácil compreensão, intuitiva e funcional, sendo as janelas gráficas as que mais agradam (Figura 6.2). Para desenvolvimento das interfaces com o usuário utilizou-se um conjunto de bibliotecas "Fast Light Tool Kit" (FLTK), o qual possui ferramentas de interface gráfica compatíveis com LINUX, OpenGL e Microsoft Windows e programação compatível com linguagem 
orientada a objetos C ++ [SPITZAK (1998)].
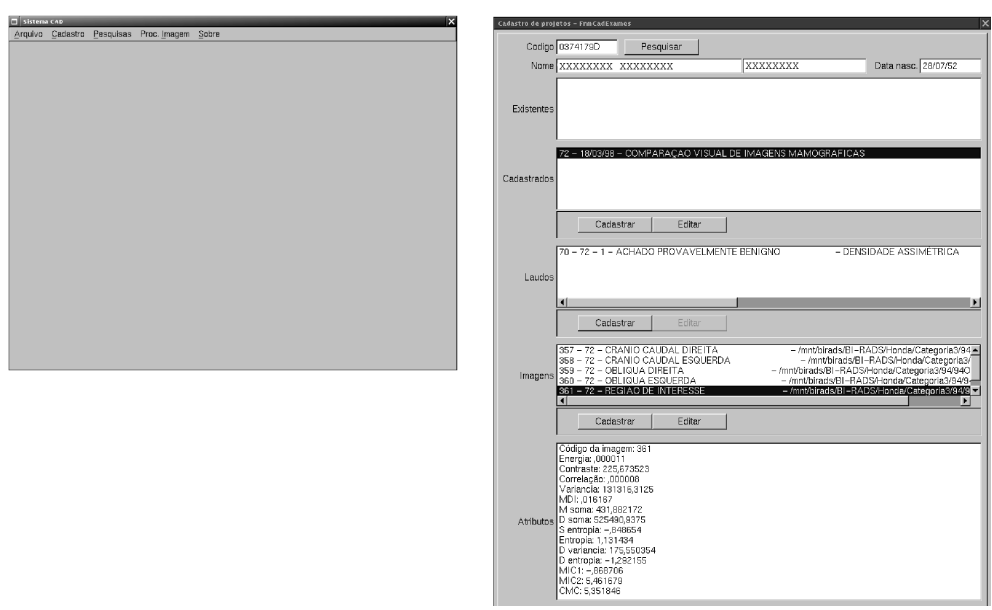

Figura 6.2: Exemplo de interfaces gráficas do sistema - menu principal e cadastro de exames

\subsection{Banco de dados}

Neste projeto utilizou-se o Sistema Gerenciador de Banco de Dados Oracle Enterprise Edition Release 8.1.6.1.0, produto da Oracle Corporation® para plataforma Intel com o sistema operacional GNU/LINUX, visando uma futura integração do sistemas de extração de atributos, indexação e recuperação de imagens pelo conteúdo com o Sistema de Informação em Radiologia (RIS) que está implantado junto ao Serviço de Radiodiagnóstico do Hospital das Clínicas da Faculdade de Medicina de Ribeirão Preto da Universidade de São Paulo [AZEVEDO-MARQUES et al. (2000)].

\subsection{Levantamento e digitalização dos exames mamográficos}

Para a obtenção dos exames mamográficos foi realizado, junto ao Serviço de Radiodiagnóstico do Hospital das Clínicas da Faculdade de Medicina de Ribeirão Preto da Universidade de São Paulo, um levantamento retrospectivo de exames seqüenciais abrangendo o período de 05/03/1998 à 23/03/1998, acompanhados dos respectivos laudos. Neste trabalho as imagens foram digitalizadas e armazenadas de modo a povoar 
o Banco de Conhecimentos (Figura 6.3), proporcionando consultas por características pictóricas das imagens. A aquisição foi feita com um digitalizador Mirage II Umax, com 12 bits de quantização (4096 níveis de cinza), 300 dpi de resolução espacial para as imagens completas e 600 dpi para as ROIs, seguindo os requisitos apontados por Chan et al. [CHAN et al. (1994)].

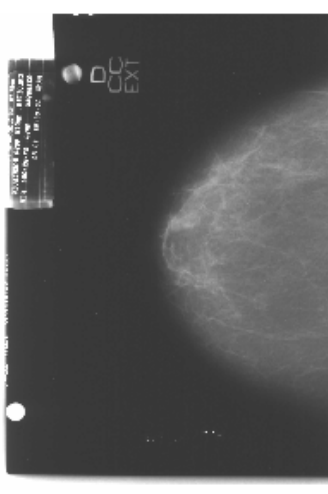

(a)

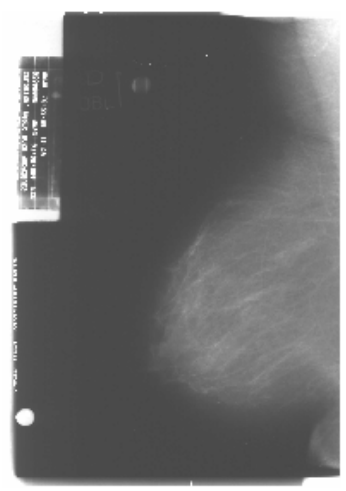

(b)

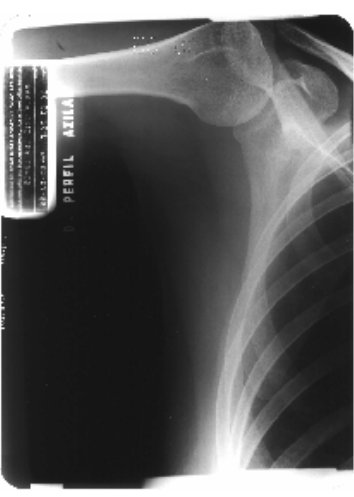

(c)

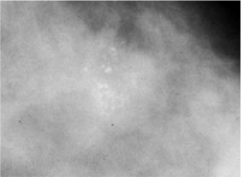

(d)

Figura 6.3: Exemplo de mamogramas digitalizados; (a) crânio caudal direita, (b) oblíqua direita, (c) axilar direita e (d) ROI.

Foram utilizadas 393 imagens, as quais se encontram distribuídas de acordo com a classificação BI-RADS, como mostrado na Tabela 6.1:

\begin{tabular}{|c|c|}
\hline Categoria & Imagens \\
\hline \hline I & 20 \\
\hline II & 146 \\
\hline III & 150 \\
\hline IV & 58 \\
\hline V & 19 \\
\hline
\end{tabular}

Tabela 6.1: Total de imagens digitalizadas por categorias

\subsection{Classificação dos mamogramas}

Os exames mamográficos foram classificados com o auxílio de médicos radiologistas do Centro de Ciências das Imagens e Física Médica da Faculdade de Medicina de Ribeirão 
Preto da Universidade de São Paulo, utilizando-se o padrão BI-RADS. Os radiologistas também estabeleceram a localização das ROIs contendo os achados radiológicos nas imagens.

\subsection{Extração de atributos de textura}

Para indexação das imagens pelo conteúdo, foram calculados para as ROIs 14 atributos de textura (Figura 6.4), sugeridos por Haralick et al. [HARALICK et al. (1973)]. A definição de cada um desses atributos encontra-se descrita no capítulo 2.

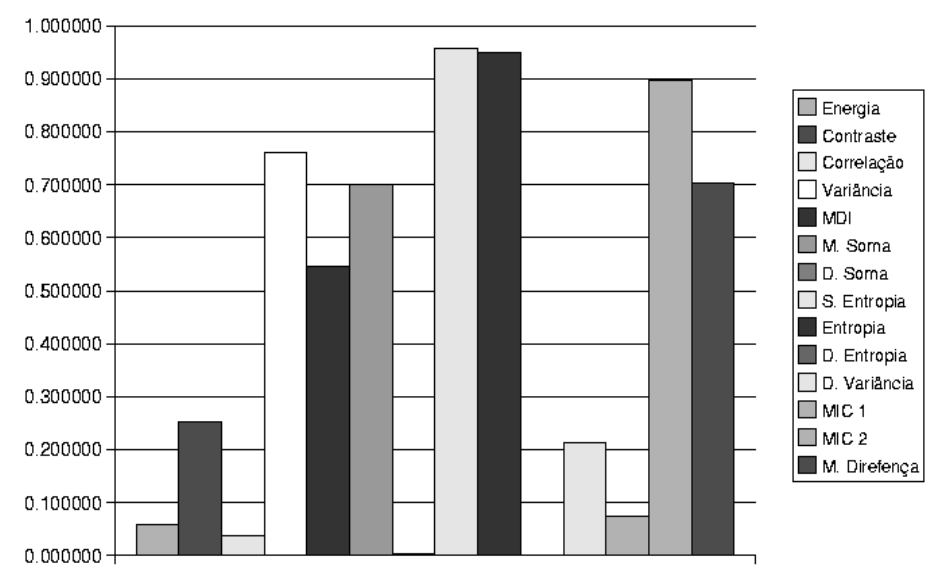

Figura 6.4: Exemplo de valores extraídos de uma ROI

Seus respectivos valores foram armazenados no Banco de Dados e relacionados com o exame cadastrado da paciente, suas imagens e laudos histopatológicos. Todos os atributos implementados e extraídos das imagens foram normalizados entre 0 e 1 utilizando a equação 6.1 :

$$
\text { Valor Normalizado }=\frac{\text { valor }}{\text { max.valor }}
$$

Os atributos de textura foram calculados à partir da matriz SGLD, a qual foi calculada variando-se os ângulos nas direções $0^{\circ}, 45^{\circ}, 90^{\circ}$ e $135^{\circ}$ (Figura 6.5), para uma 
distância entre pares de "pixel" de $d=1$. Desta forma, a matriz SGLD resultante é uma média de 4 matrizes, de acordo com cada ângulo de direção e com informações da probabilidade de "pixels" vizinhos com distância igual a um terem o mesmo valor de nível de cinza. Além disso, a matriz SGLD resultante é normalizada através da divisão de cada elemento pelo número total de elementos contidos na matriz, conforme sugerido por Haralick et al. [HARALICK et al. (1973)].

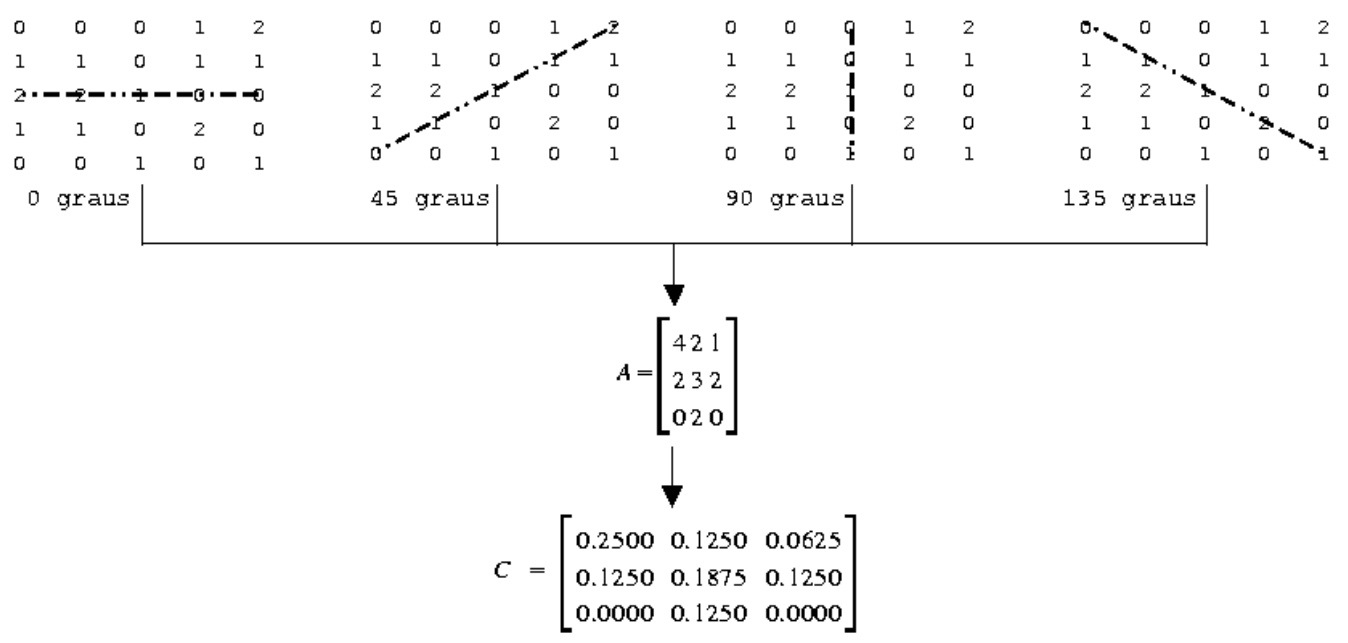

Figura 6.5: Calculo da matriz SGLD

Para simplificar o processo de indexação e recuperação das imagens foi utilizado para reduzir o número de atributos de textura e as redundâncias de informações existentes, o PCA, demonstrado na figura 6.6, que é um método de Análise Multivalorada, o qual é um ramo da estatística responsável por examinar como variáveis dependentes relacionam-se dentro de um determinado conjunto de dados. Ou seja, trabalham reduzindo o número de variáveis ou eliminando variáveis difíceis de serem discriminadas, com um mínimo de perda de informações relevantes. 


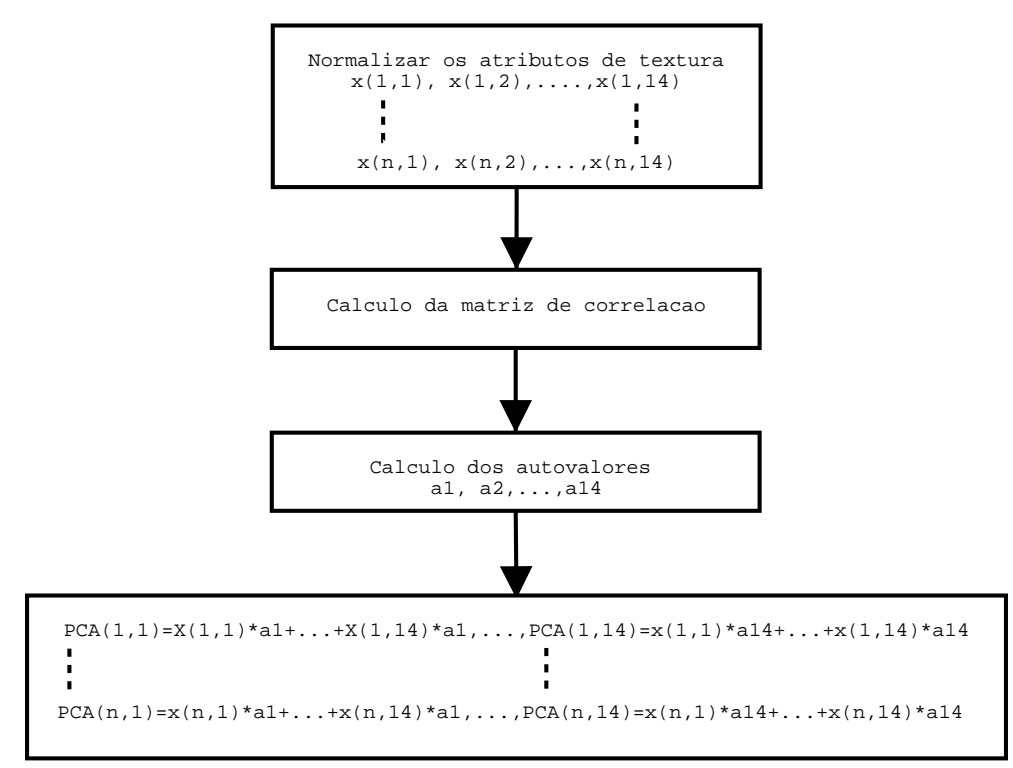

Figura 6.6: Resumo dos passos para Análise de Componentes Principais

\subsection{Indexação e recuperação das imagens pelo conteúdo}

Para indexação e recuperação das imagens foram utilizadas como índice e elementos de consultas, os 6 primeiros coeficientes de componentes principais, que juntos somam um valor acumulado de $91.62 \%$ do total da variância, as outras 8 componentes principais foram descartadas por não possuírem valores significativos de variância (Tabela 6.2).

\begin{tabular}{|c|c|c|}
\cline { 2 - 3 } \multicolumn{1}{c|}{} & Autovalores & \% acumulada \\
\hline 1 & 7.003812655 & 50.027233 \\
\hline 2 & 2.017385752 & 64.437131 \\
\hline 3 & 1.111104386 & 72.373591 \\
\hline 4 & 0.999867423 & 79.515502 \\
\hline 5 & 0.876632747 & 85.777164 \\
\hline 6 & 0.816800504 & 91.611453 \\
\hline 7 & 0.570324103 & 95.685197 \\
\hline
\end{tabular}

\begin{tabular}{|c|c|c|}
\cline { 2 - 3 } \multicolumn{1}{c|}{} & Autovalores & \% acumulada \\
\hline 8 & 0.331534898 & 98.053303 \\
\hline 9 & 0.205450140 & 99.520804 \\
\hline 10 & 0.050083058 & 99.878540 \\
\hline 11 & 0.016123286 & 99.993707 \\
\hline 12 & 0.000590231 & 99.997923 \\
\hline 13 & 0.000230152 & 99.999567 \\
\hline 14 & 0.000060666 & 100.000000 \\
\hline
\end{tabular}

Tabela 6.2: Autovalores gerados pelo PCA

Para a consulta abranger uma faixa de valores, foi utilizada a porcentagem dos valores variando-os para mais e para menos os valores da imagem utilizada como busca. Estas porcentagem foram testadas com vários valores até $100 \%$, demonstrando que o percentual de $15 \%$ foi o que na média retornou um número mais aceitável de ima- 
gens. O sistema permite que o usuário defina este percentual, dependendo do tipo de desempenho desejado (maior sensibilidade ou maior especificidade). A combinação dos atributos nas consultas foi feita utilizando-se um operador lógico do tipo "and", um exemplo da consulta é demonstrado na figura 6.7.

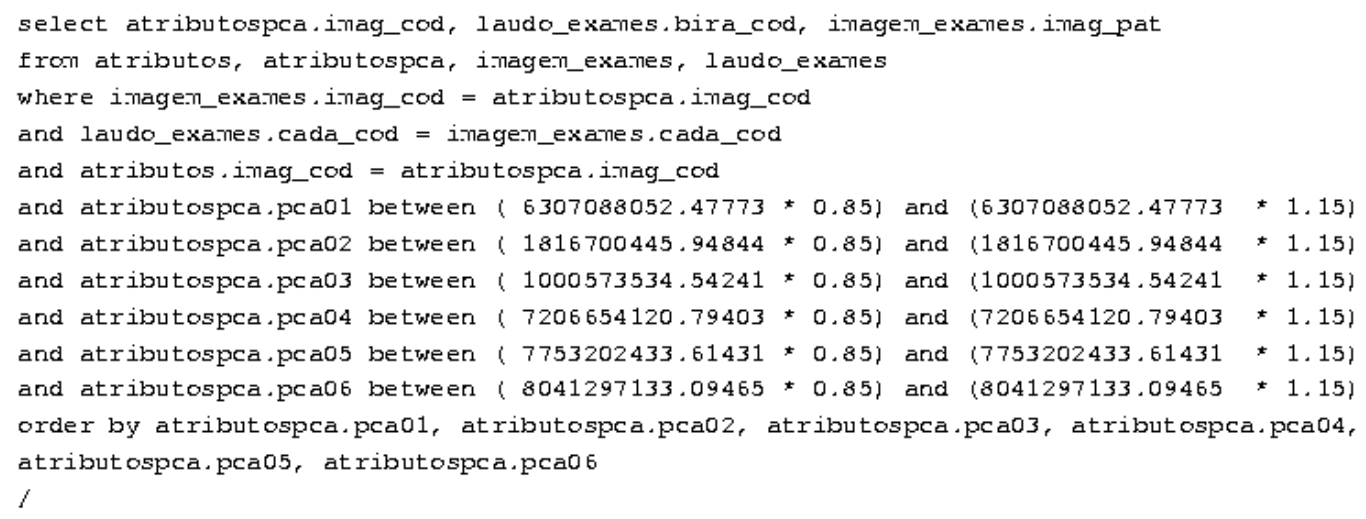

Figura 6.7: Exemplo de um código de consulta

\subsection{Interface de visualização}

Também com o auxílio de médicos radiologistas do Centro de Ciências das Imagens

e Física Médica da Faculdade de Medicina de Ribeirão Preto da Universidade de São Paulo, foi desenvolvida uma interface de visualização das imagens (Figura 6.8), que permite a abertura simultânea das duas vistas das imagens e entre outras características um rápido navegador.

\subsection{Avaliação de resultados}

$\mathrm{Na}$ maioria dos sistemas de indexação e recuperação de dados, tempo e espaço requerido são usualmente as métricas utilizadas para avaliação do sistema. Já em sistemas projetados para indexação e recuperação de informações, outras métricas além de tempo e espaço são de interesse. Esses sistemas de recuperação de informações necessitam da análise do grau de similaridade (classificação) dentro do conjunto recuperado, o que aca- 


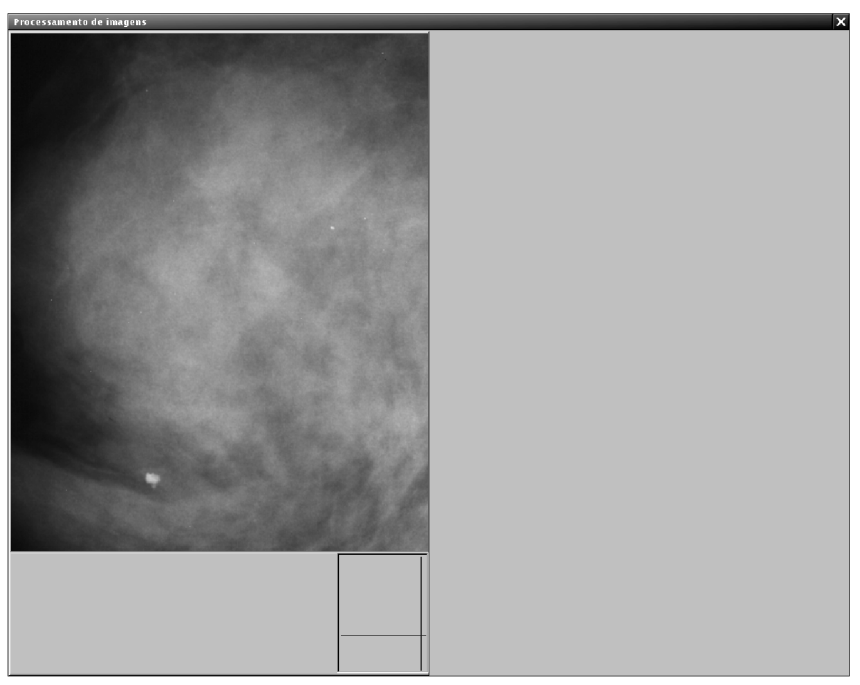

Figura 6.8: Visualizador de imagens

ba exigindo formas complementares de avaliação. Notadamente alguma forma quantitativa associada a uma outra qualitativa [BAEZA-YATES \& RIBEIRO-NETO (1999)].

Em nosso caso específico, sendo a proposta o auxílio ao diagnóstico à partir de inspeção visual, a avaliação de desempenho torna-se muito complicada, pois é inerente a proposta de um sistema de recuperação de informações, a recuperação de imagens semelhantes, porém com laudos diferentes, implicando necessariamente em uma avaliação qualitativa de similaridade por parte do médico. Neste contexto, a avaliação do desempenho do sistema é bastante difícil e sujeita a grandes variações de resposta intra e inter observador. Porém, como a avaliação de desempenho é fundamental para qualquer sistema de busca e recuperação de imagens, optou-se por fazer a quantificação do desempenho a partir da avaliação qualitativa do médico. Para tanto, foram tomadas de forma aleatória (por sorteio) algumas imagens de ROIs, a saber 4 ROIs de categoria II, 5 ROIs de categoria III e 4 ROIs de categoria IV do BI-RADS. A categoria I pertencente a mamas com nenhum achado, não tiveram ROIs selecionadas e a categoria $\mathrm{V}$ por possuir um número pequeno de casos não ocorreu nenhuma vez.

As imagens das ROIs recuperadas foram apresentadas a um especialista (Dr. J. A. H. R.), juntamente com a imagem da ROI utilizada para busca, o qual classificou a 
similaridade entre 1 e 5 , segundo a tabela 6.3 .

\begin{tabular}{|c|c|}
\hline Índice & Descrição \\
\hline \hline 1 & Completamente diferente \\
\hline 2 & Parcialmente diferente \\
\hline 3 & Semelhante \\
\hline 4 & Parcialmente idêntico \\
\hline 5 & Completamente idêntico \\
\hline
\end{tabular}

Tabela 6.3: Îndice de similaridade

Foram também apresentadas ao médico especialista as imagens completas dos casos recuperados e a de referência, para uma nova avaliação de similaridade (Figura 6.9). Em princípio, a avaliação somente das ROIs fornece informações de similaridade diretamente relacionadas à imagem da região de interesse, ao passo que, a avaliação do caso completo fornece informações relacionadas ao uso de imagens para o auxílio ao diagnóstico. As avaliações qualitativas do especialista foram utilizadas para o calculo da Precisão do sistema [BAEZA-YATES \& RIBEIRO-NETO (1999)] e [TAKAHASHI et al. (2000)], onde:

$$
\text { Precisão }=\frac{\text { Número de recuperadas relevantes }}{\text { Total de recuperadas }}
$$

Neste trabalho foram consideradas relevantes as imagens recuperadas que tiveram nota maior ou igual a 3. O valor do "threshold" para recuperação das imagens foi definido através de uma avaliação qualitativa do médico especialista, que considerou como a melhor situação uma variação de $15 \%$ nos valores dos atributos das imagens, resultando em um número de imagens recuperadas aproximadamente igual a 10 . 

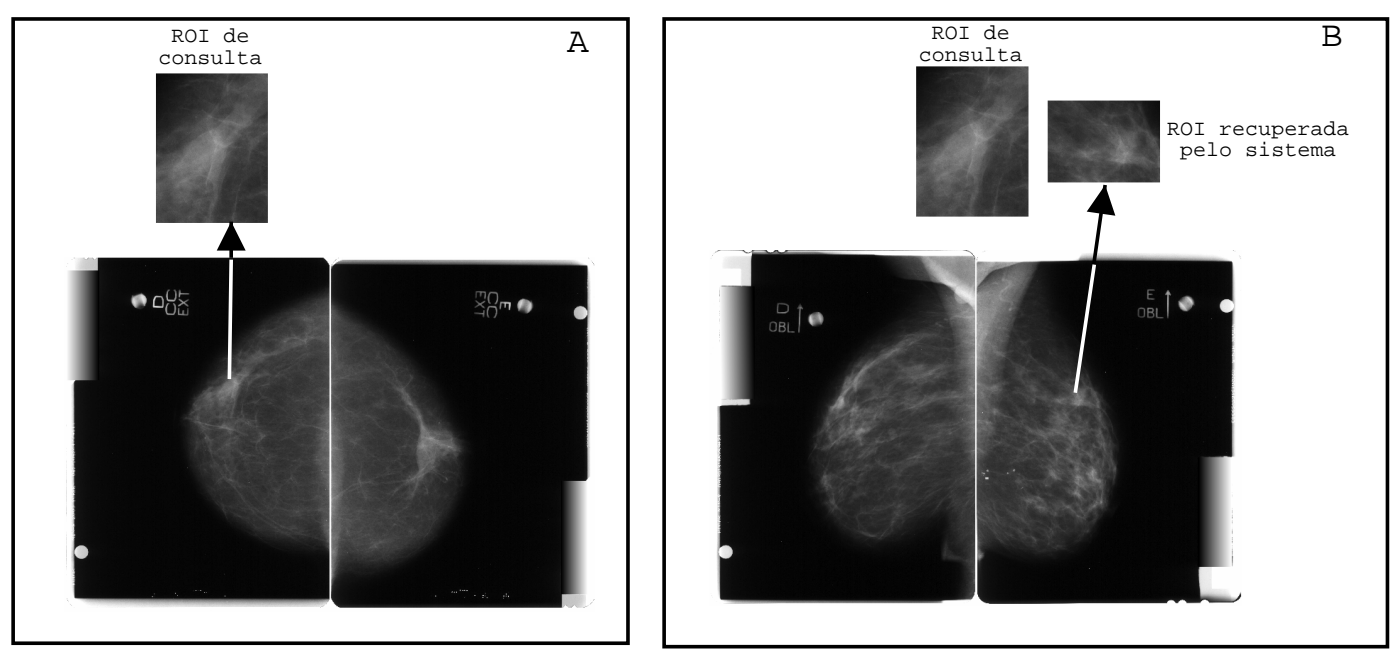

Figura 6.9: No conjunto de imagens (A) é apresentado a ROI utilizada para consulta com suas respectivas imagens e no conjunto de imagens (B) é apresentado a ROI recuperada pelo sistema com suas respectivas imagens 


\section{Capítulo 7}

\section{Resultados e discussão}

A partir da metodologia apresentada, os resultados da indexação e recuperação de imagens mamográficas pelo conteúdo serão apresentados.

\subsection{Precisão do sistema de recuperação de imagens}

A tabela 7.1 apresenta o resultado da avaliação do especialista e cálculo de Precisão para as imagens recuperadas para cada uma das ROIs utilizadas na consulta e a tabela 7.2 o mesmo resultado para avaliação dos casos completos.

\begin{tabular}{|c|c|c|c|c|}
\hline ROIs & BI-RADS & Recuperadas & Relevantes & Precisão \\
\hline \hline 5 & II & 13 & 6 & 0.46 \\
\hline 13 & II & 4 & 2 & 0.50 \\
\hline 23 & II & 9 & 2 & 0.22 \\
\hline 33 & III & 7 & 3 & 0.43 \\
\hline 40 & III & 3 & 3 & 1.00 \\
\hline 59 & III & 7 & 6 & 0.86 \\
\hline 108 & II & 9 & 2 & 0.22 \\
\hline 129 & IV & 7 & 5 & 0.71 \\
\hline 139 & IV & 10 & 8 & 0.80 \\
\hline 145 & IV & 14 & 8 & 0.57 \\
\hline 152 & IV & 11 & 5 & 0.45 \\
\hline 161 & III & 15 & 6 & 0.40 \\
\hline 208 & III & 14 & 5 & 0.36 \\
\hline
\end{tabular}

Tabela 7.1: Resultado da avaliação do especialista e valor de Precisão para ROIs 


\begin{tabular}{|c|c|c|c|c|}
\hline ROIs & BI-RADS & Recuperadas & Relevantes & Precisão \\
\hline \hline 5 & II & 13 & 4 & 0.31 \\
\hline 13 & II & 4 & 2 & 0.50 \\
\hline 23 & II & 9 & 4 & 0.44 \\
\hline 33 & III & 7 & 4 & 0.57 \\
\hline 40 & III & 3 & 3 & 1.00 \\
\hline 59 & III & 7 & 5 & 0.71 \\
\hline 108 & II & 9 & 3 & 0.33 \\
\hline 129 & IV & 7 & 3 & 0.43 \\
\hline 139 & IV & 10 & 5 & 0.50 \\
\hline 145 & IV & 14 & 5 & 0.36 \\
\hline 152 & IV & 11 & 8 & 0.73 \\
\hline 161 & III & 15 & 7 & 0.47 \\
\hline 208 & III & 14 & 6 & 0.43 \\
\hline
\end{tabular}

Tabela 7.2: Resultado da avaliação do especialista e valor de Precisão para os casos completos

Analisando-se a Tabela 7.1 pode-se observar que houve uma variação bastante grande no valor obtido para a precisão em cada uma das consultas, incluindo desde valores muito baixos para as ROIs 23 e 108 (Precisão $=0.22$ ), até valores mais altos como para as ROIs 139 (Precisão $=0.80)$ e $59($ Precisão $=0.86)$ e um valor de $100 \%$ de acerto para a ROI 40. Uma amplitude de variação semelhante é apresentada na Tabela 7.2. Pode-se notar também que o número total de imagens recuperadas também variou bastante (mínimo $=3$ para a ROI 40 e máximo $=15$ para a ROI 161). É provável que a grande variação tanto nos valores de precisão, como também no número total de imagens recuperadas por consulta, seja um indicativo de que as imagens utilizadas não representaram, numericamente, de forma adequada todos os tipos de lesões existentes no banco. O número total de imagens utilizadas foi relativamente alto (393 imagens), porém parece não ter sido suficiente para garantir uma representatividade adequada dentro de todas as categorias. Provavelmente um aumento no número de amostras no banco deverá produzir resultados mais uniformes no processo de recuperação de imagens. Outro aspecto importante que deve ser observado refere-se ao fato de ter sido utilizado um operador lógico do tipo "and" para composição dos atributos de textura 
no processo de recuperação das imagens. A escolha deste operador foi uma tentativa de conseguir uma forma simples de composição dos atributos, que possibilitasse a obtenção de resultados com maior precisão. Certamente, o uso deste operador lógico também contribui para que algumas consultas retornassem um número reduzido de imagens. Por outro lado, deve ter contribuído também para que se tivesse um acerto de $100 \%$ na consulta baseada na ROI 40. Uma alternativa ao uso do classificador "and" seria a utilização de um operador lógico do tipo "or" para a composição dos atributos de textura, o que aumentaria o número de imagens recuperadas, associado a um filtro do tipo "matching", o qual selecionaria as imagens mais próximas da imagem de referência a partir do cálculo de uma medida de similaridade, como correlação, por exemplo. Outra possibilidade seria o uso de um classificador propriamente dito, como uma ANN, por exemplo. Provavelmente, uma modificação deste tipo no processo de seleção das imagens deverá aumentar tanto a sensibilidade como a precisão do sistema de recuperação de imagens baseada em conteúdo. Um aspecto fundamental, porém, que deve ser ressaltado, é que todas as consultas realizadas resultaram em pelo menos uma imagem considerada relevante (nota mínima de similaridade igual a 3, ou seja, semelhante), o que indica a possibilidade do uso do sistema para auxílio ao diagnóstico uma vez que, ficaria a critério do médico escolher entre as imagens apresentadas as que, segundo sua opinião, seriam semelhantes ao caso desconhecido e solicitar ao sistema a recuperação dos laudos associados. De modo geral, os valores apresentados nas Tabelas 7.1 e 7.2 são concordantes, apesar de alguma variação, indicando que, quando as ROIs são consideradas semelhantes, o caso todo tende a ser também considerado semelhante. Este resultado indica uma tendência favorável ao uso de imagens exemplo, mesmo que somente de regiões de interesse, como referência para buscas em sistemas de recuperação de imagens baseada em conteúdo visando ao auxílio ao diagnóstico médico. Porém, três consultas apresentaram resultados bastante diferentes no que se refere a avaliação das ROIs e dos casos completos. As consultas a partir das ROIs 129 e 139 apresentaram resultados de precisão iguais a 0.71 para as ROIs contra 0.43 para o caso completo e 
0.80 para as ROIs contra 0.50 , respectivamente, indicando que, embora separadamente as imagens das regiões de interesse sejam parecidas, não apresentam significado relevante quando inseridas no contexto dos casos como um todo. Por outro lado, a consulta baseada na ROI 152 apresentou resultado de precisão igual a 0.45 para as ROIs contra 0.73 para o caso completo, indicando que, embora individualmente as ROIs não tenham sido consideradas semelhantes, os casos como um todo foram considerados parecidos, podendo ser utilizados como referência uns para os outros. Novamente, os resultados obtidos apontam para a necessidade de uma avaliação mais precisa baseada no uso de um número muito maior de casos, particularmente no que se refere ao impacto do uso de imagens semelhantes, com laudos conhecidos, no desempenho do médico na avaliação de casos desconhecidos.

A tabela 7.3 apresenta o valor médio e desvio padrão da precisão, calculada para as ROIs, por categorias das imagens utilizadas para a consulta e o valor médio e o desvio padrão globais (calculados entre as categorias). A tabela 7.4 apresenta o mesmo cálculo para a avaliação dos casos completos.

\begin{tabular}{|c|c|c|}
\hline Categoria & Média & Desvio padrão \\
\hline \hline II & 0.38 & 0.13 \\
\hline III & 0.61 & 0.30 \\
\hline IV & 0.64 & 0.15 \\
\hline Todas & 0.55 & 0.23
\end{tabular}

Tabela 7.3: Média e desvio padrão na avaliação das ROIs

\begin{tabular}{|c|c|c|}
\hline Categoria & Média & Desvio padrão \\
\hline \hline II & 0.40 & 0.09 \\
\hline III & 0.64 & 0.23 \\
\hline IV & 0.50 & 0.16 \\
\hline Todas & 0.52 & 0.19
\end{tabular}

Tabela 7.4: Média e desvio padrão na avaliação dos casos completos

As tabelas 7.3 e 7.4 apresentam uma visão global do desempenho do sistema de recuperação de imagens baseada em conteúdo. Pode-se notar que, embora algumas categorias, representadas pelas imagens utilizadas para a consulta, tenham alcançado va- 
lores um pouco mais elevados, na média os valores de precisão obtidos são relativamente baixos, porém os altos valores obtidos para o desvio padrão espelham a grande variação de desempenho obtida entre as amostras utilizadas. Como citado anteriormente, é provável que o aumento do número de amostras existentes no banco, em conjunto com a mudança no processo de seleção das imagens, deva aumentar o valor médio da precisão para o sistema. Por outro lado, as pequenas variações apresentadas entre as tabelas de avaliação de desempenho global para as ROIs separadamente e para os casos completos, tendem a confirmar a possibilidade do uso de regiões de interesse como imagens de referência para a recuperação de informação visando o auxílio ao diagnóstico.

A figura 7.1 apresenta as imagens e as notas dadas pelo especialista para a consulta com o maior valor de precisão, a figura 7.2 para uma consulta com valor de precisão intermediário e a figura 7.3 para a consulta com o menor valor de precisão. As demais imagens apresentadas para avaliação do especialista e cálculo de Precisão são apresentadas nas figuras $9.1,9.2,9.3,9.4,9.5,9.6,9.7,9.8,9.9$ e 9.10, no capítulo anexos.
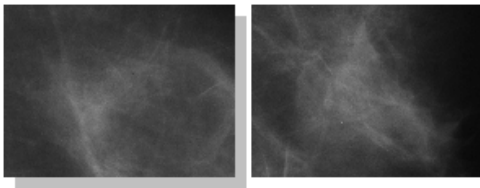

A - III $5-$ IV

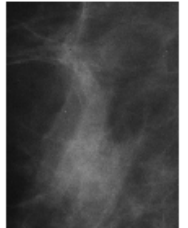

$5-I V$

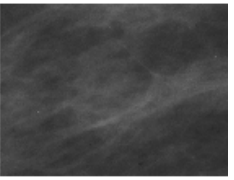

$4-$ III

Figura 7.1: (A) imagem utilizada para consulta - imagem 40 $\mathrm{Na}$ legenda são apresentadas as classificações dadas pelo médico radiologista para cada ROI seguida da sua classificação segundo o padrão BI-RADS

A partir das imagens apresentadas nas figuras 7.1, 7.2 e 7.3 é possível se ter uma idéia do processo de avaliação realizado pelo médico especialista e do que foi por ele considerado semelhante ou não. Deve-se novamente ressaltar que, mesmo nos casos que obtiveram o pior resultado de precisão, sempre existiu pelo menos uma imagem considerada semelhante, o que indica o potencial do método no auxílio ao diagnóstico a partir da recuperação de informações baseada do conteúdo pictórico de imagens de referência. Porém, é importante salientar que este tipo de avaliação (qualitativa) é 

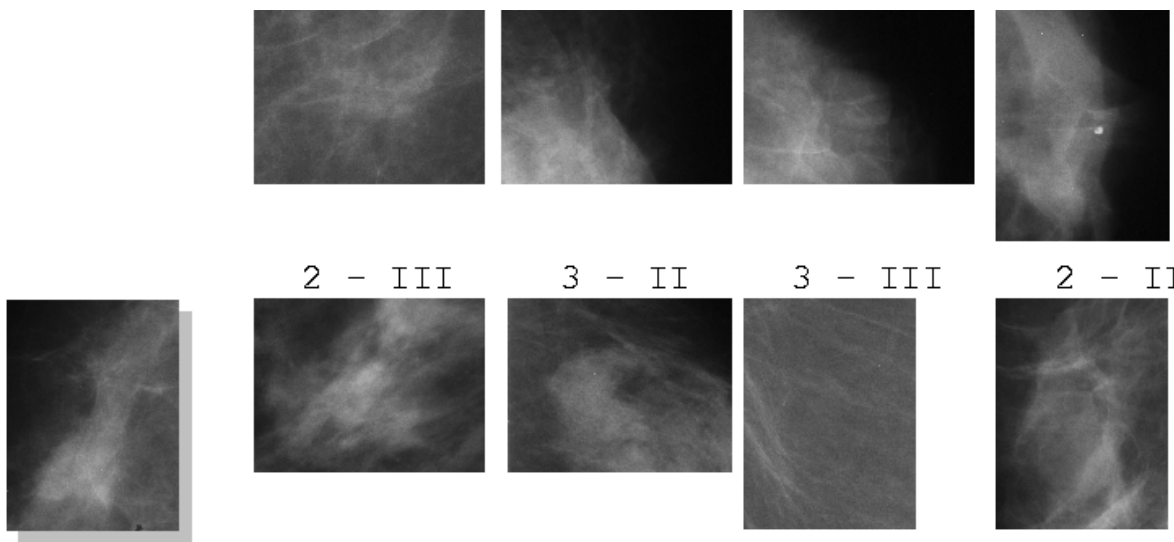

$3-$ III

$2-I I$

A - IV
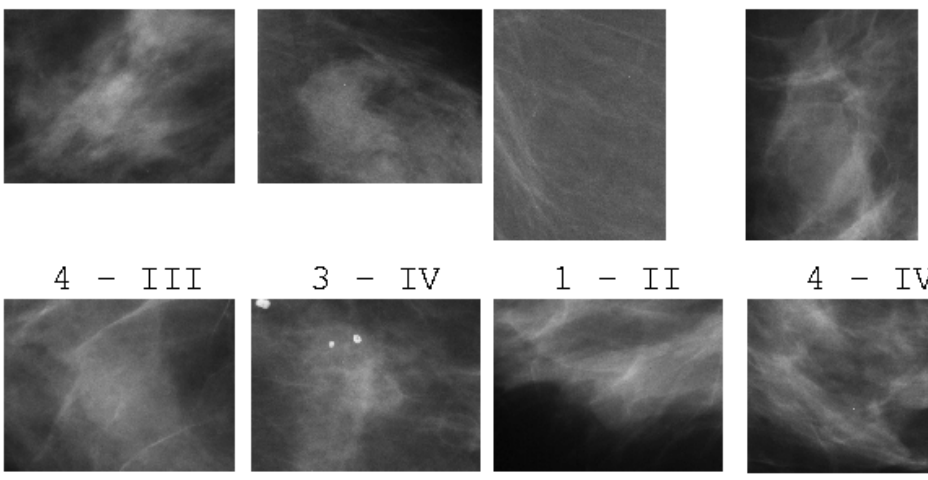

$1-I I$

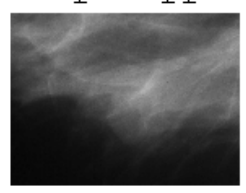

$4-I V$
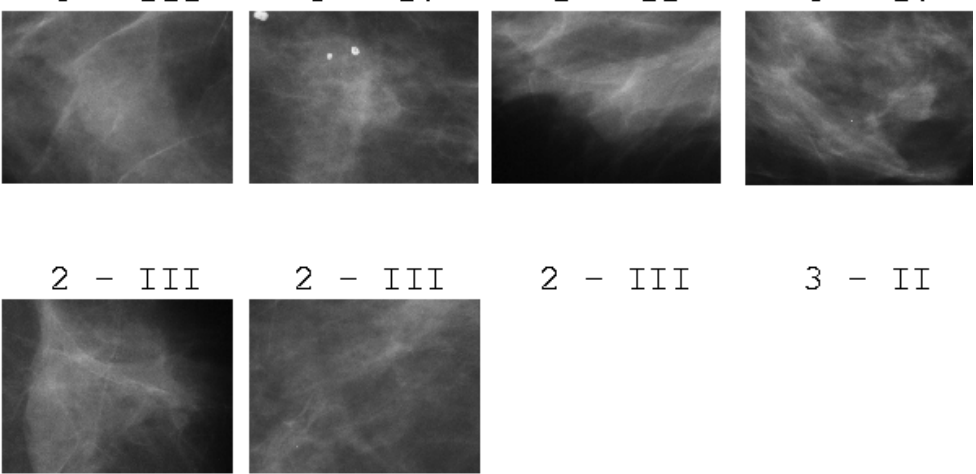

$2-\operatorname{III}$

$2-\operatorname{III}$

$3-$ II

4 - IV 3 - III

Figura 7.2: (A) imagem utilizada para consulta - imagem 145

$\mathrm{Na}$ legenda são apresentadas as classificações dadas pelo médico radiologista para cada ROI seguida da sua classificação segundo o padrão BI-RADS 


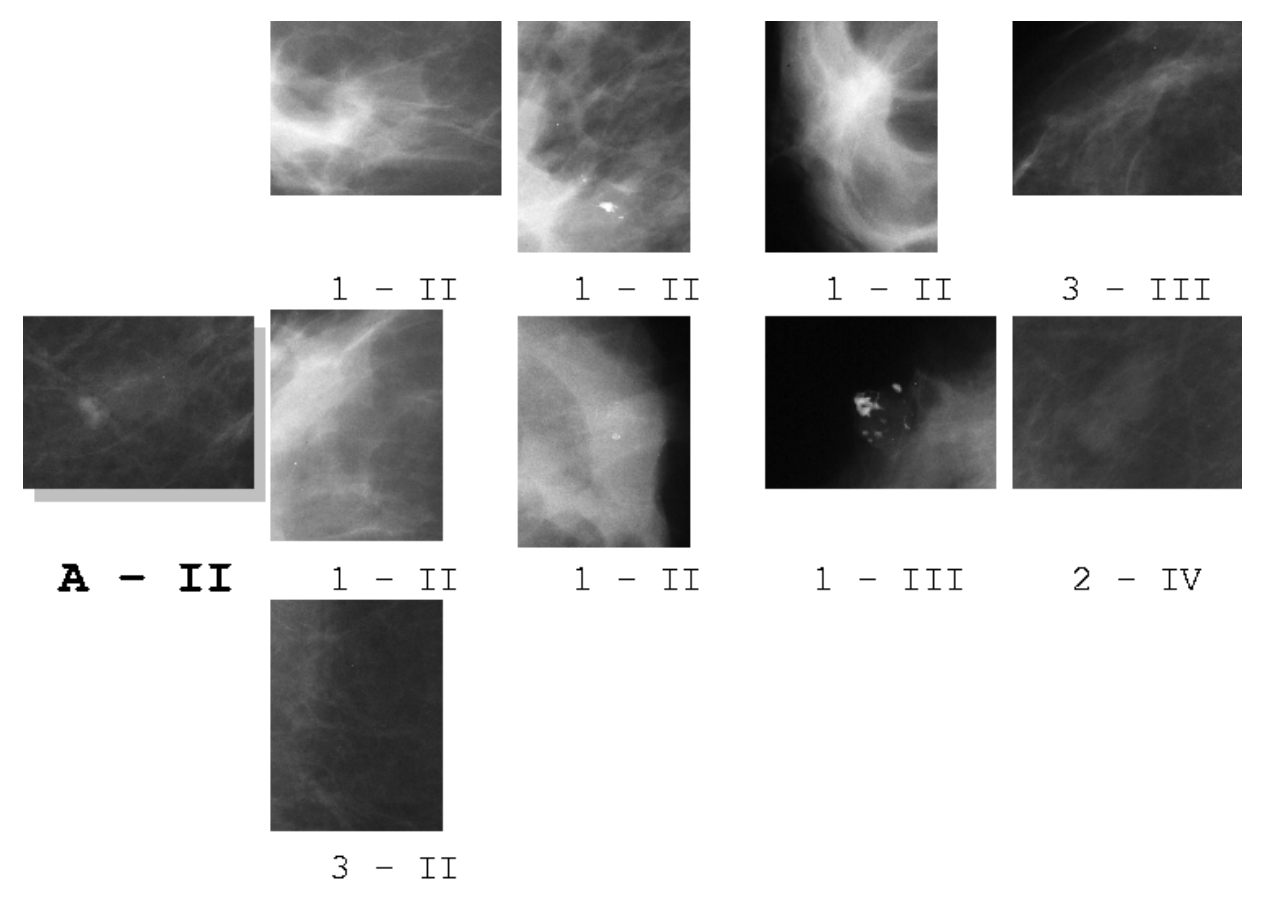

Figura 7.3: (A) imagem utilizada para consulta - imagem 108

$\mathrm{Na}$ legenda são apresentadas as classificações apresentada pelo médico radiologista e respectivamente sua classificação segundo o BI-RADS

extremamente subjetiva e está sujeita a variações intra e inter pessoais, e um estudo com um número maior de médicos especialistas deve ser realizado. 


\section{Capítulo 8}

\section{Conclusões}

\subsection{Conclusões finais}

A recente explosão no volume de informação disponível em sistemas hospitalares tem criado um grande aumento de demanda pelo arquivamento de dados multimídia em sistemas de bancos de dados integrados. Particularmente na Radiologia, com o aumento do uso de equipamentos de imagem digital, a busca por informações neste formato tem ganhado importância rapidamente. A Recuperação baseada em conteúdo é uma alternativa importante e um complemento fundamental para os sistemas tradicionais de busca baseados em "palavras-chave", especialmente no que se refere ao gerenciamento dos dados em Sistemas de Informação com Suporte a Imagens. Em um sistema de recuperação de imagens baseada em conteúdo, atributos das imagens como cor, textura e forma são automaticamente extraídos no processo de indexação, quando novas imagens são inseridas na base de dados, e consultas e recuperação de informações podem ser baseadas diretamente nas propriedades visuais das imagens, retornando valores ordenados segundo o grau de similaridade de conteúdo. A descrição das propriedades visuais pode ser feita de várias maneiras, incluindo descrição de conteúdo, representações por esboço ou ícones ou o uso de imagens exemplos. Neste trabalho foi estudado e implementado um sistema de recuperação de imagens baseada em conteúdo voltado para o 
auxílio ao diagnóstico de lesões de mama. O sistema permite a recuperação de laudos de imagens conhecidas a partir da consulta feita por atributos extraídos de uma região de interesse obtida de uma imagem desconhecida. De modo geral os resultados obtidos indicaram a viabilidade de utilização do esquema proposto para o auxílio ao diagnóstico, porém maiores estudos são necessários, particularmente no que se refere ao uso de um número maior de casos para montagem do banco de conhecimentos, melhoria no processo de seleção das imagens e avaliação do desempenho baseada na resposta de um número maior de médicos especialistas. Porém, pode-se concluir que:

1. A metodologia proposta apresenta um grande potencial de representatividade em imagens mamográficas digitalizadas. Foram investigados atributos de textura e métodos de redução e seleção de atributos (PCA).

2. Os resultados demonstraram que o esquema proposto apresenta melhor resultado para imagens contendo regiões de interesse com nódulos associados.

\subsection{Sugestões para trabalhos futuros}

Apesar dos resultados obtidos demonstrarem várias qualidades importantes para indexação e recuperação de imagens baseadas no conteúdo em mamogramas digitalizados, provavelmente pode-se melhorá-lo acrescentando ou substituindo algumas características:

1. Utilizar bases de dados publicadas para aumentar o número de amostras, procurando com isto, um alto grau de representatividade de uma amostra de imagem dentro de uma população de casos (por exemplo a "Digital Database for Screening Mammography" (DDSM) da Universidade do Sul da Florida - que pode ser encontrada em http://marathon.csee.usf.edu/Mammography/Database.html).

2. Investigação e extração de outros atributos, tendo como objetivo uma maior aproximação com a inspeção visual humana. 
3. Deve-se fazer um estudo de métodos de classificação, como, por exemplo ANN, para utilização em conjunto com um número maior de amostras e outros atributos de extração de características, tornando o sistema de indexação e recuperação de imagens pelo conteúdo também um sistema de classificação automatizado do padrão BI-RADS.

4. Deve-se implementar outros métodos de recuperação de imagens baseados no conteúdo. Um exemplo, a utilização de imagens padrão para busca.

5. Implantação de técnicas de segmentação de imagens que possam separar a região de tecido mamário do fundo do filme (exemplo figura 8.1), possibilitando a seleção automática de regiões para extração de atributos.
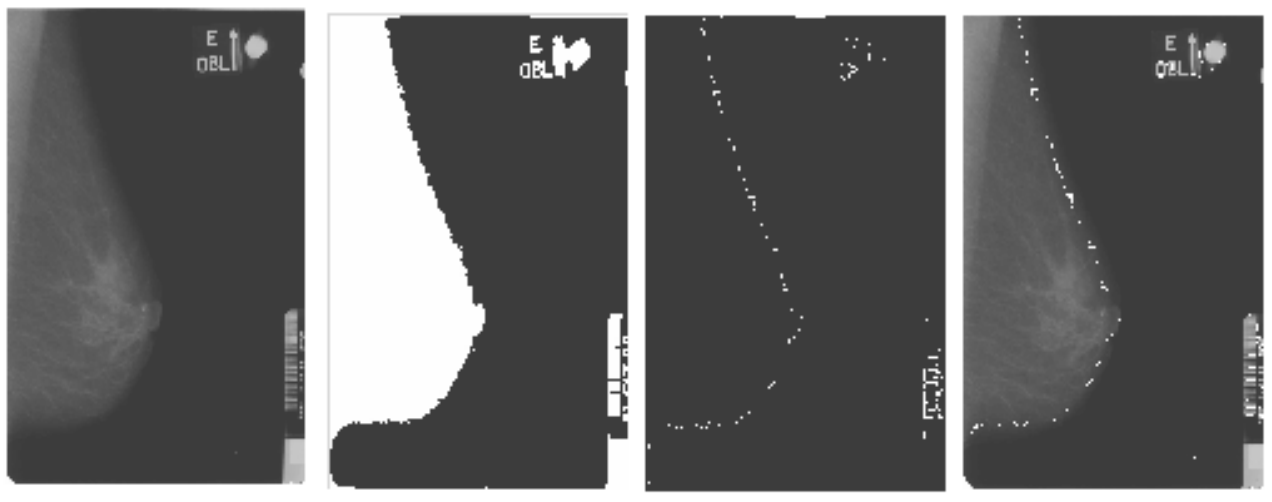

Figura 8.1: Exemplo de técnica de segmentação de imagens para separar o tecido mamário do fundo do filme (Cedido por Roberto Rodrigues Pereira Junior SEL/EESC/USP)

6. Estudo do impacto da recuperação e exibição de imagens similares no desempenho dos radiologistas no processo de classificação das lesões da mama. 


\title{
Capítulo 9
}

\begin{abstract}
Anexos
As figuras que apresentamos a seguir, foram relacionadas aqui porque a sua extensão tornaria cansativa a interpretação do texto, porém são importantes para compreensão deste trabalho. As figuras relacionadas a seguir apresentam a ROI utilizada para consulta com sua classificação do BI-RADS e as respectivas ROIs recuperadas pelo sistema com a classificação apresentada pelo radiologista para cada ROI seguida de sua classificação segundo o padrão BI-RADS.
\end{abstract}



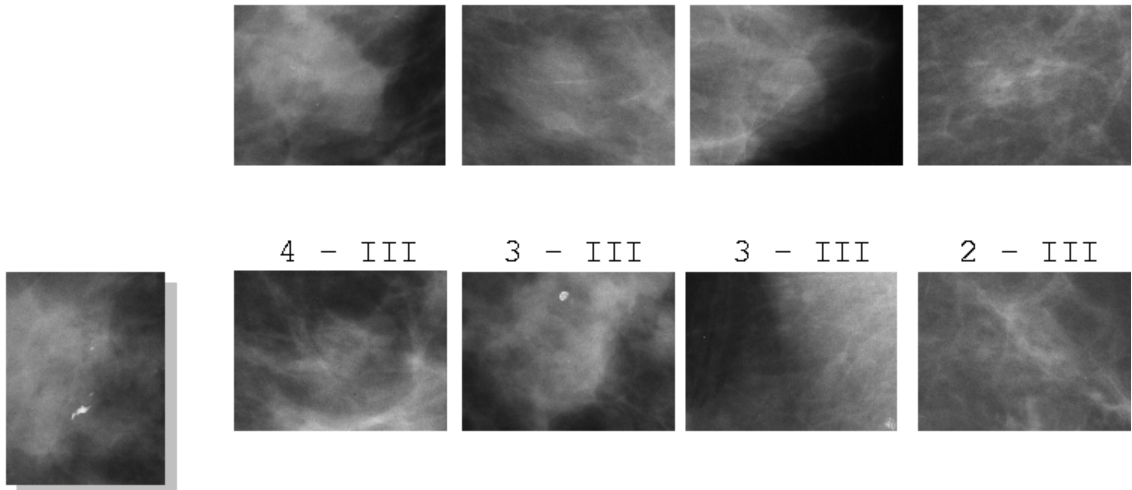

A II
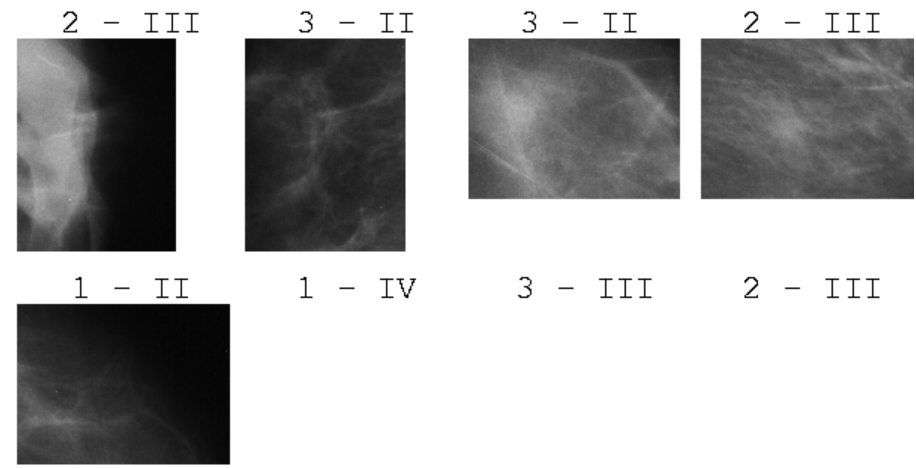

$2-\operatorname{III}$

$1-\operatorname{III}$

Figura 9.1: (A) imagem utilizada para consulta - imagem 5

$\mathrm{Na}$ legenda são apresentadas as classificações dadas pelo médico radiologista para cada ROI seguida da sua classificação segundo o padrão BI-RADS

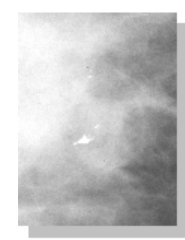

$A-I I$

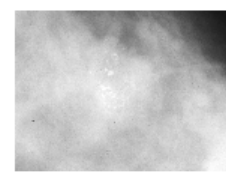

$3-V$

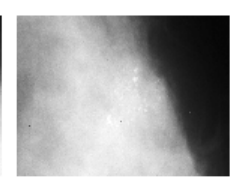

$3-\mathrm{V}$

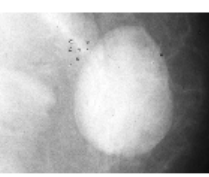

$1-I V$

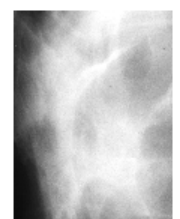

$2-$ II

Figura 9.2: (A) imagem utilizada para consulta - imagem 13

$\mathrm{Na}$ legenda são apresentadas as classificações dadas pelo médico radiologista para cada ROI seguida da sua classificação segundo o padrão BI-RADS 


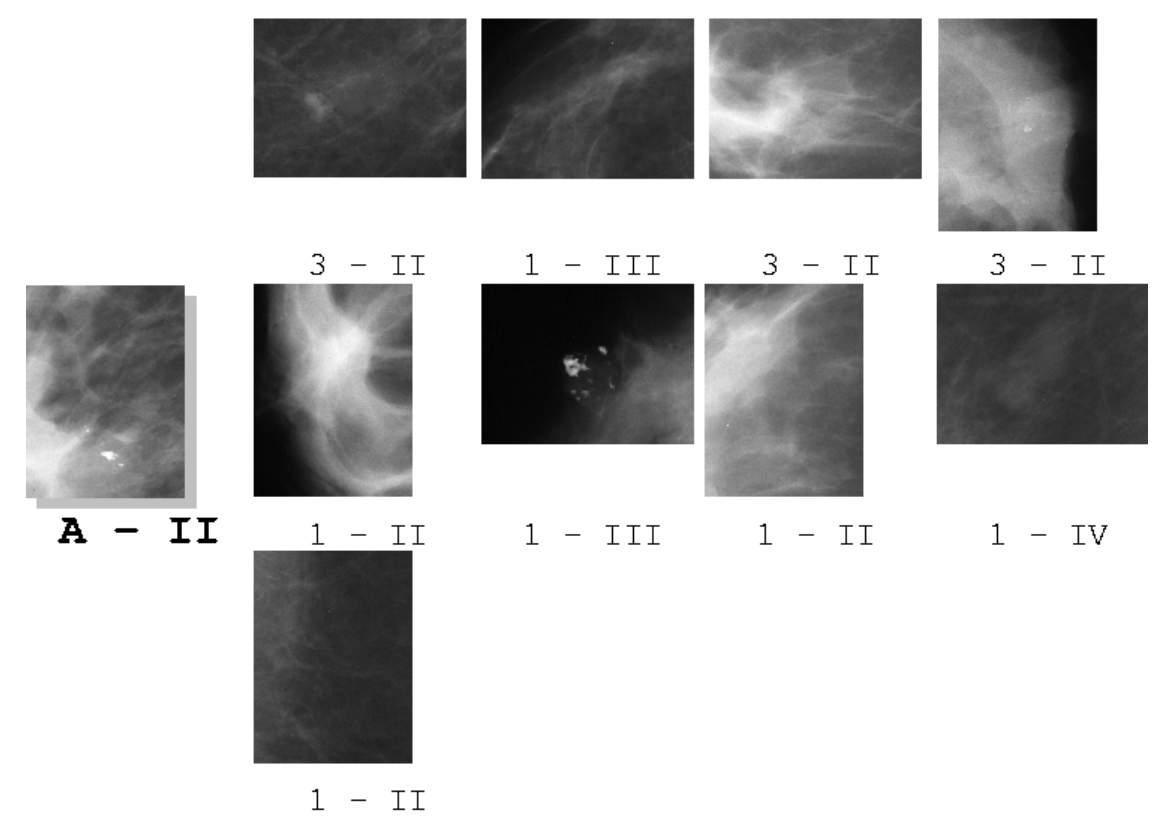

Figura 9.3: (A) imagem utilizada para consulta - imagem 23

$\mathrm{Na}$ legenda são apresentadas as classificações dadas pelo médico radiologista para cada ROI seguida da sua classificação segundo o padrão BI-RADS
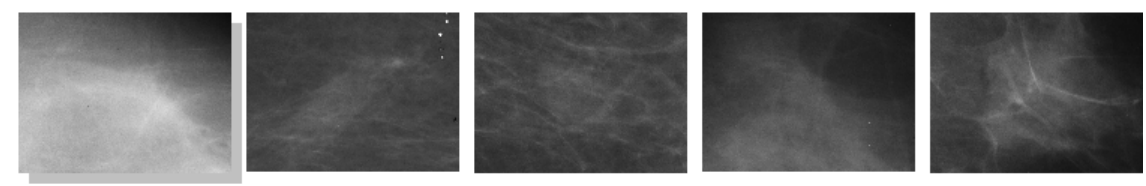

A - III
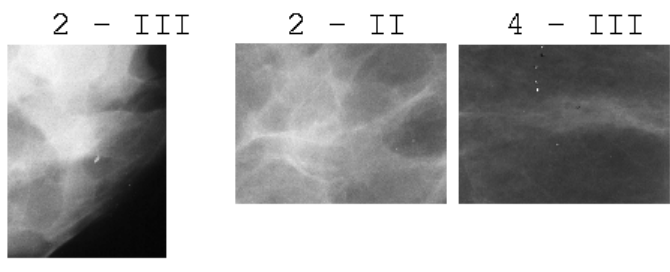

$3-$ IV

$1-I I$

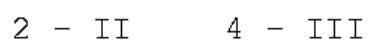

Figura 9.4: (A) imagem utilizada para consulta - imagem 33

$\mathrm{Na}$ legenda são apresentadas as classificações dadas pelo médico radiologista para cada ROI seguida da sua classificação segundo o padrão BI-RADS 

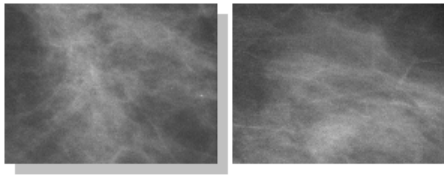

A - III

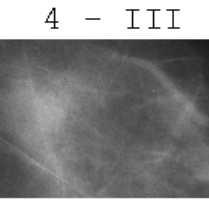

$3-\operatorname{III}$
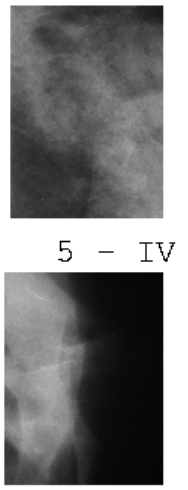

$1-$ II
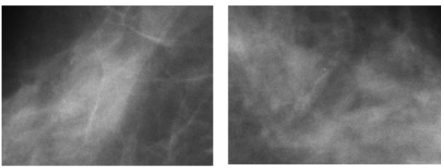

$4-\mathrm{V}$

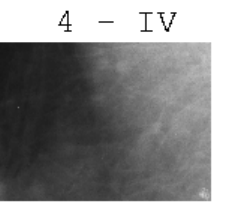

$4-$ II

Figura 9.5: (A) imagem utilizada para consulta - imagem 59

$\mathrm{Na}$ legenda são apresentadas as classificações dadas pelo médico radiologista para cada ROI seguida da sua classificação segundo o padrão BI-RADS
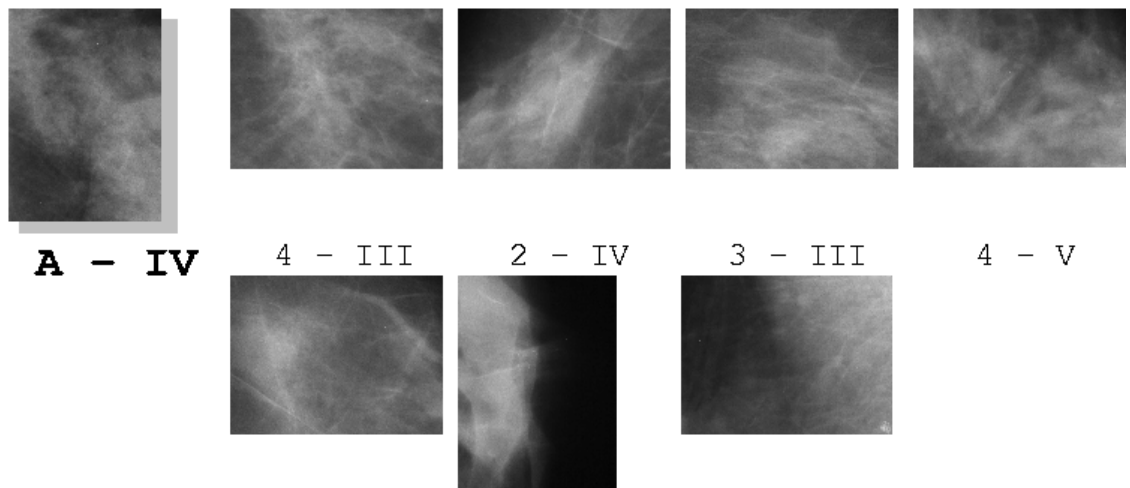

$4-\mathrm{V}$

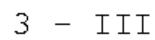

$2-I I$

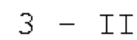

Figura 9.6: (A) imagem utilizada para consulta - imagem 129

$\mathrm{Na}$ legenda são apresentadas as classificações dadas pelo médico radiologista para cada ROI seguida da sua classificação segundo o padrão BI-RADS 


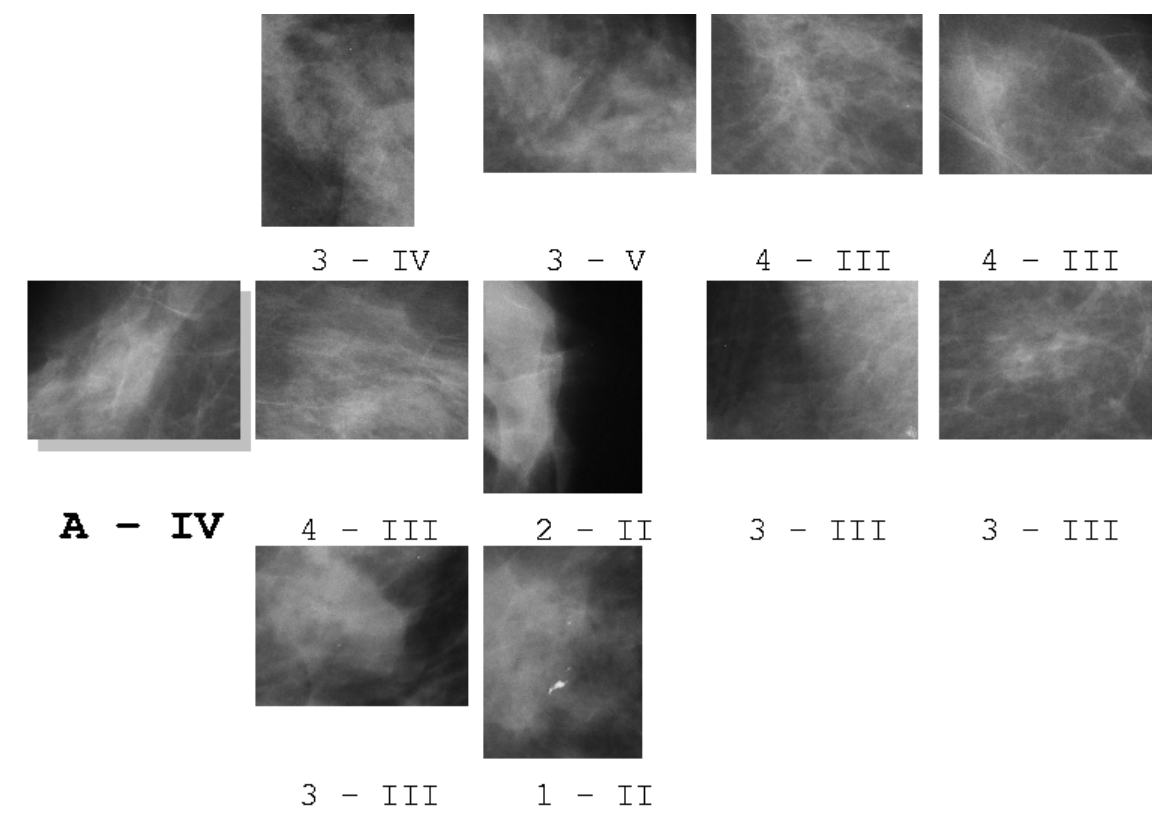

Figura 9.7: (A) imagem utilizada para consulta - imagem 139

$\mathrm{Na}$ legenda são apresentadas as classificações dadas pelo médico radiologista para cada ROI seguida da sua classificação segundo o padrão BI-RADS
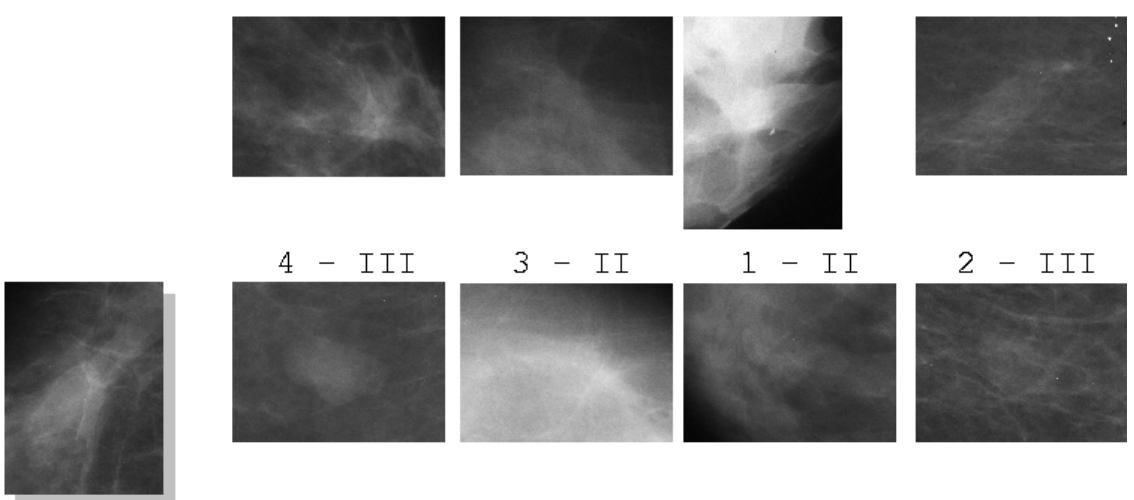

$3-$ II

$1-I I$

$2-\operatorname{III}$
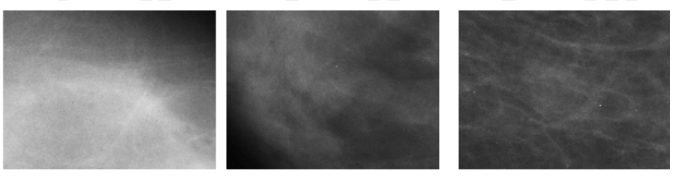

A - IV
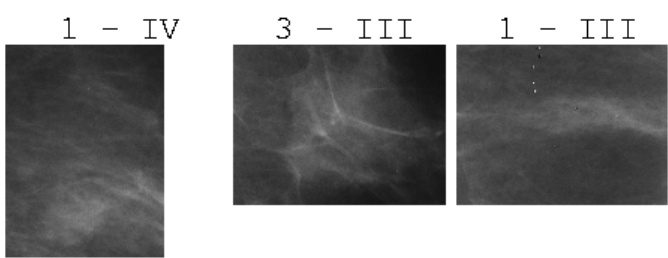

$2-I I$

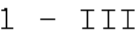

$3-I V$

$3-$ III

Figura 9.8: (A) imagem utilizada para consulta - imagem 152

$\mathrm{Na}$ legenda são apresentadas as classificações dadas pelo médico radiologista para cada ROI seguida da sua classificação segundo o padrão BI-RADS 


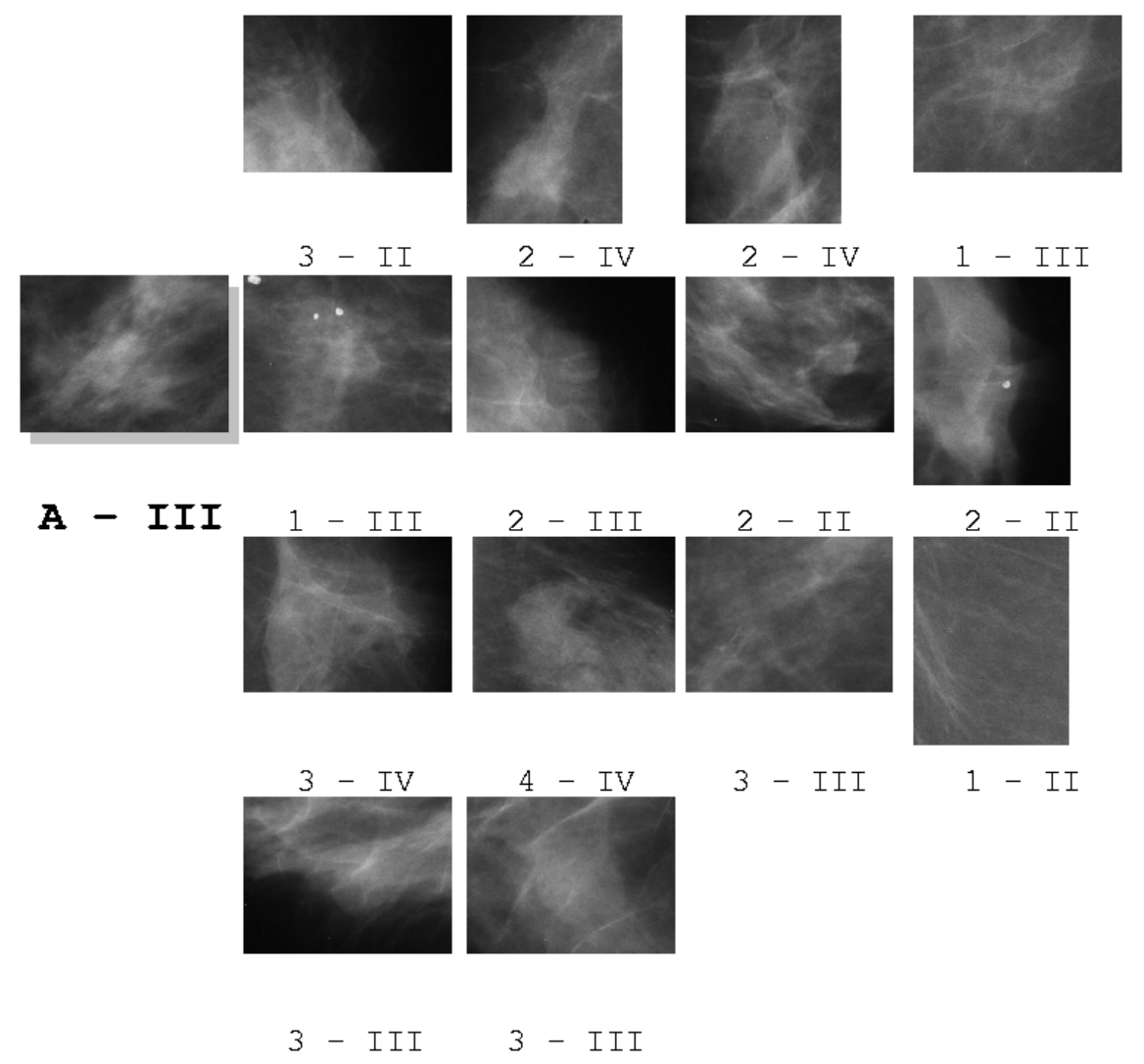

Figura 9.9: (A) imagem utilizada para consulta - imagem 161

$\mathrm{Na}$ legenda são apresentadas as classificações dadas pelo médico radiologista para cada ROI seguida da sua classificação segundo o padrão BI-RADS 

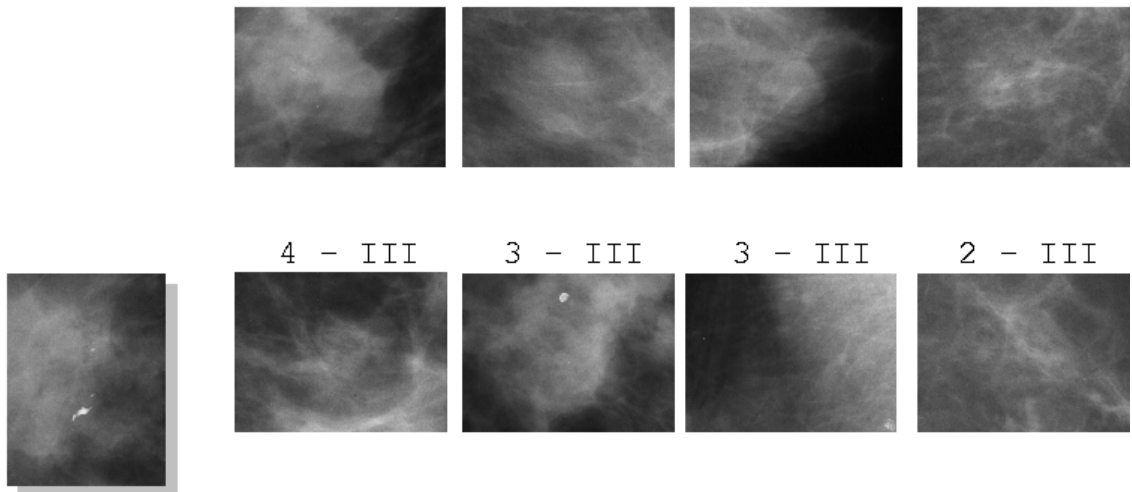

A II
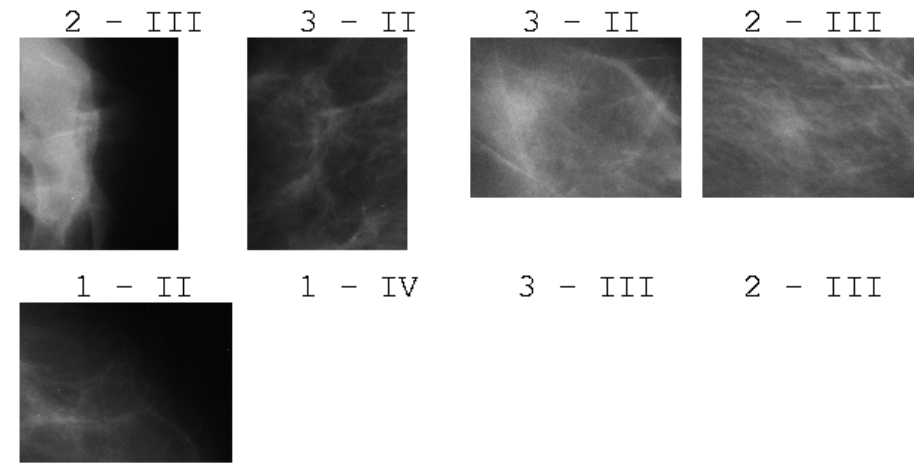

$3-\operatorname{III}$

$2-\operatorname{III}$

$1-$ III

Figura 9.10: (A) imagem utilizada para consulta - imagem 208

$\mathrm{Na}$ legenda são apresentadas as classificações dadas pelo médico radiologista para cada ROI seguida da sua classificação segundo o padrão BI-RADS 


\section{Referências Bibliográficas}

[AZEVEDO-MARQUES et al. (2000)] AZEVEDO-MARQUES, P., SANTOS, A., ELIAS-JÚNIOR, J., GOES, W., CASTRO, C., e TRAD, C. Implantação de um sistema de informação em radiologia em hospital universitário. Radiologia Brasileira, (no. 33):pp. 155-160, 2000.

[BAEZA-YATES \& RIBEIRO-NETO (1999)] BAEZA-YATES, R. e RIBEIRO-NETO, B. Modern information retrieval. ACM Press Books, United States, 1999. ISBN 0201-39823-X.

[BALLARD \& BROWN (1982)] BALLARD, D. e BROWN, C. Computer vision. Pretice Hall Inc., Englewwod Clifs, New Jersey, 1982.

[BASSET et al. (1993)] BASSET, O., SUN, Z., MESTAS, J., e GIMENEZ, G. Texture analysis of ultrasonic images of the prostate by means of co-occurrence matrices. (no. 15):pp. 218-237, 1993.

[BAUAB (2000)] BAUAB, S. Lesões provavelmente benignas classificação III do BIRADS. Jornal da Imagem, (no. 260):2o. caderno, pp. A-1, 2000.

[BAUAB et al. (1999)] BAUAB, S., TAJARA, L., e PINHO, M. Classificação imaginológica das lesões mamárias. Jornal da Imagem, (no. 247):20. caderno, A-2, 1999.

[BI-RADS (1998)] BI-RADS. Illustrated breast imaging reporting and data system. American College of Radiology, third edition edition, 1998. Reston [VA]: American College of Radiology. 
[BONTRAGER (1999)] BONTRAGER, K. Tratado de técnica radiológica e base anatômica. Editora Guanabara Koogan S.A., 4 edition, 1999.

[CASTLEMAN (1996)] CASTLEMAN, K. Digital image processing. Perceptive Scientific Instruments, Prentice Hall Inc., New Jersey, 1996.

[CHAN et al. (1998)] CHAN, H., SAHINER, B., PETRICK, N., HELVIE, M., GOODSITT, M., e ADLER, D. Computadorized analysis of mammographic microcalcifications in morphological and texture features spaces. Medical Physics, vol. 25(no. 10):pp. 2007-2019, 1998.

[CHAN et al. (1994)] CHAN, H.-P., NIKLASON, L., IKEDA, D., LAM, K.-L., e ADLER, D. Digitization requerements in mammography: effects on computer-aided detection of microcalcifications. Medical Physics, vol. 21(no. 7):pp. 1203-1211, 1994.

[DAVIES \& DANCE (1990)] DAVIES, D. e DANCE, D. Automatic computer detection of clustered calcifications in digital mammograms. Physics in Medicine and Biology, vol. 35(no. 8):pp. 1111-1118, 1990.

[EGAN et al. (1980)] EGAN, R., McSWEENWY, M., e SEWELL, C. Intramammary calcifications without an associated mass in benign and malignant diseases. Radiology, 1980.

[ELMASRI \& NAVATHE (1989)] ELMASRI, R. e NAVATHE, S. Fundamentals of database systems. The Benjamin Cummings Plublishing Company, 1989.

[FERRARI et al. (1999)] FERRARI, R., AZEVEDO-MARQUES. P.M., SLAETS A.F.F., KINOSHITA, S., e SPINA, L. Characterization of breast cancer using statical approaches. Computer-Aided Diagnosis in Medical Imaging, Excerpta Medical, International Congress Serie II 82, pages pp. 281-296, 1999. 
[FREDERICK (2000)] FREDERICK, E. Computer aided diagnosis of acute pulmonary embolism. Tese de Doutoramento, Department of biomedical Engineering - Duke University, 2000.

[GIGER (1999)] GIGER, M. Computer-aided diagnosis. RSNA Categorical, Course in Breast Imaging, pages pp. 249-272, 1999.

[GONZALEZ \& WOODS (1993)] GONZALEZ, R. e WOODS, R. Digital image processing. Addilson Wesley Publishing Company, United States, 1993. ISBN 0-20150803-6.

[GUTTA et al. (1998)] GUTTA, S., BALA, J., HADJARIAN, A., TRACHIOTIS, S., PACHOWICZ, P., e GOGIA, B. Mammographic region of interest database retrieval and indexing engine. Digital Mammography, Nijmegen, Kluwer Academic Publishers, 1998. ISBN 0-7923-5274-2.

[HARALICK et al. (1973)] HARALICK, R., SHANMUGAN, K., e DINSTEIN, I. Testural features of images classification. IEEE Transactions on System, Man and Cibernetics SMC-3, (no. 6):pp. 610-621, 1973.

[INCA (2001)] INCA. Estimativa da incidendia e mortalidade por câncer no Brasil 2000. Instituto Nacional do Câncer - Ministério da Saúde, Coordenação de Programas de Câncer, http://www.inca.org.br/, 2001.

[KIM \& PARK (1999)] KIM, J. e PARK, H. Statical texture features for detection of microcalcifications in digitized mammograms. IEEE Transactions on System on Medical Imaging, vol. 18(no. 3):pp. 231-238, 1999.

[KINOSHITA et al. (1999)] KINOSHITA, S., AZEVEDO-MARQUES, P., SLAETS A, F., MARANA, H., e FERRARI, R. Characterization of breast masses using texture and shape features. Computer-Aided Diagnosis in Medical Imaging, Excerpta Medical, International Congress Serie II 82, pages pp. 265-270, 1999. 
[KOCUR et al. (1996)] KOCUR, C., ROGERS, S., MYERS, L., BURNS, T., KABRISKY, M., HOFFMEISTER, J., BAUER. K.W., e STEPPE, J. Using neural networks to select wavelet features for breast cancer diagnosis. IEEE Engineering in Medicine and Biology, 1996.

[KORTH \& SILBERSCHATZ (1994)] KORTH, H. e SILBERSCHATZ, A. Sistema de banco de dados. Makron Books, 1994.

[LAINE et al. (1995)] LAINE, A., FAN, J., e YANG, W. Wavelets for contrast enhancement of digital mammography. IEEE Engineering in Medicine and Biology, pages pp. 536-550, 1995.

[LEFEBVRE et al. (1994)] LEFEBVRE, F., BENALI, H., GILLES, R., e PAOLA, R. Simulation model of clustered breast microcalcifications. Medical Physics, vol. 21(no. 12):pp. 1866-1874, 1994.

[LIN et al. (1999)] LIN, H.-C., WANG, L.-L., e YANG, S.-N. Regular-texture image retrieval based on texture-primitive extraction. Image and vision computing, (no. 17):pp. 51-63, 1999.

[LOW (1991)] LOW, A. Introductory computer vision and image processing. MacGraw Hill Book Company, London, 1991.

[MORROW et al. (1992)] MORROW, W., PARANJAPE, R., RANGAYYAN, R., e DESAUTELS, J. Region-based contrast enhancement of mammograms. IEEE Transactions on Medical Imaging, vol. 11(no. 3), 1992.

[MUDIGONDA et al. (2000)] MUDIGONDA, N., RANGAYYAN, R., e DESAUTELS, J. Gradient and texture analysis for the classification of mammographic masses. IEEE Transactions on Medical Imaging, vol. 19(no. 10):pp. 1032-1043, 2000. 
[PETRICK et al. (1996)] PETRICK, N., CHAN, H.-P., SAHINER, B., e WEI, D. An adaptive density-weighted contrast enhancement filter for mammographic breast mass detection. IEEE Transactions on Medical Imaging, vol. 15(no. 1):pp. 59-67, 1996.

[PETROSIAN et al. (1994)] PETROSIAN, A., CHAN, H., HELVIE, M., GOODSITT, M., e ADLER, D. Computer-aided diagnosis in mammography: classification of mass and normal tissue by texture analysis. Physics in Medicine and Biology, vol. 39:pp. 2273-2289, 1994.

[QI \& SNYDER (1999)] QI, H. e SNYDER, W. Content-based image retrieval in picture archiving and communications systems. Journal of Digital Imaging, vol. 12(no. 2, suppl. 1):pp. 81-83, 1999.

[RICHARDSON (1995)] RICHARDSON, W. Applying wavelets to mammograms. IEEE Engineering in Medicine and Biology, pages pp. 551-560, 1995.

[SCHILDT (1998)] SCHILDT, S. C++: the complete reference. Brandon A. Nordin Publisher, third edition edition, 1998.

[SHEN et al. (1993)] SHEN, L., RANGAYYAN, R., e DESAUTELS, J. Detection and classification of mammographic calcifications. International Journal of Pattern Recognition and Artificial Intelligence, vol. 7(no. 6):pp. 1403-1416, 1993.

[SPITZAK (1998)] SPITZAK, B. FLTK documentation. http://www.fltk.org/documentation.html, 1998.

[TAKAHASHI et al. (2000)] TAKAHASHI, N., IWASAKI, M., KUNIEDA, T., WAKITA, Y., e DAY, N. Image retrieval using spatial intensity features. Signal Processing Image Communication, (no. 16):pp. 45-57, 2000.

[TOURASSI (1999)] TOURASSI, G. Journey toward computer-aided diagnosis: role of image texture analysis. Radiology, vol. 213(no. 2):pp. 317-320, 1999. 
[VINCE et al. (2000)] VINCE, D., DIXON, K., COTHREN, R., e CORNHILL, J. Comparison of testure analysis methods for the characterization of coronary plaques in intravascular ultrasound images. Computerized Medical Imaging and Graphics, (no. 24):pp. 221-229, 2000.

[WOODS et al. (1994)] WOODS, K., SOLKAR, J., PRIEBE, C., e KEGELMEYER, W. Comparative evalution of pattern recognition techniques for detection of microcalcifications in mammograms. State of the art in digital mammographic analysis. Word Scientific, pages pp.841-852, 1994. New Jersey. 